NBER WORKING PAPER SERIES

\title{
OPTIMAL OPERATIONAL MONETARY POLICY IN THE CHRISTIANO-EICHENBAUM-EVANS MODEL OF THE U.S. BUSINESS CYCLE
}

\author{
Stephanie Schmitt-Grohé \\ Martín Uribe \\ Working Paper 10724 \\ http://www.nber.org/papers/w10724
NATIONAL BUREAU OF ECONOMIC RESEARCH 1050 Massachusetts Avenue
Cambridge, MA 02138

August 2004

We are grateful to the Institute for International Economic Studies in Stockholm for its hospitality during part of the writing of this paper. We thank seminar participants at the 2004 NBER Summer Institute for comments. Newer versions of this paper are maintained at http://www.econ.duke.edu/ uribe. The views expressed herein are those of the author(s) and not necessarily those of the National Bureau of Economic Research.

(C2004 by Stephanie Schmitt-Grohé and Martín Uribe. All rights reserved. Short sections of text, not to exceed two paragraphs, may be quoted without explicit permission provided that full credit, including (C) notice, is given to the source. 
Optimal Operational Monetary Policy in the Christiano-Eichenbaum-Evans Model of the U.S. Business Cycle

Stephanie Schmitt-Grohé and Martín Uribe

NBER Working Paper No. 10724

August 2004

JEL No. E52, E61, E63

\section{ABSTRACT}

This paper identifies optimal interest-rate rules within a rich, dynamic, general equilibrium model that has been shown to account well for observed aggregate dynamics in the postwar United States. We perform policy evaluations based on second-order accurate approximations to conditional and unconditional expected welfare. We require that interest-rate rules be operational, in the sense that they include as arguments only a few readily observable macroeconomic indicators and respect the zero bound on nominal interest rates. We find that the optimal operational monetary policy is a realinterest-rate targeting rule. That is, an interest-rate feedback rule featuring a unit inflation coefficient, a mute response to output, and no interest-rate smoothing. Contrary to existing studies, we find a significant degree of optimal inflation volatility. A key factor driving this result is the assumption of indexation to past inflation. Under indexation to long-run inflation the optimal inflation volatility is close to zero. Finally, we show that initial conditions matter for welfare rankings of policies.

Stephanie Schmitt-Grohé

Department of Economics

Duke University

P.O. Box 90097

Durham, NC 27708

and NBER

grohe@duke.edu
Martín Uribe

Department of Economics

Duke University

P.O. Box 90097

Durham, NC 27708

and NBER

uribe@duke.edu 


\section{Introduction}

Optimal monetary policy is the subject of a large and fast growing body of research in macroeconomics. A central characteristic of all existing studies is that optimal monetary policy is derived in highly stylized environments. Typically, optimal monetary policy is characterized for economies with a single or a very small number of deviations from the frictionless neoclassical paradigm. A case in point are the numerous recent studies concerned with optimal policy within the context of the two-equation, one-friction, neo-Keynesian model without capital accumulation. ${ }^{1}$ Other cases in which the optimal monetary policy design problem is studied within theoretical frameworks featuring a small number of rigidities include models with distorting income taxes (Lucas and Stokey, 1983; Schmitt-Grohé and Uribe, 2004a), and models with sticky product and factor prices (Erceg, et al., 2000). An advantage of this stylized approach is that it facilitates understanding the ways in which monetary policy should respond to mitigate the distortionary effects of a particular friction in isolation.

An important drawback of studying optimal monetary policy one distortion at a time is that highly simplified models are unlikely to provide a satisfactory account of cyclical movements for more than just a few macroeconomic variables of interest. For this reason, the usefulness of this strategy to produce policy advice for the real world is necessarily limited.

The approach to optimal monetary policy that we propose in this paper departs from the literature extant in that it is based on a rich theoretical framework capable of explaining observed business cycle fluctuations for a wide range of nominal and real variables. Following the lead of Kimball (1995), the model emphasizes the importance of combining nominal as well as real rigidities in explaining the propagation of macroeconomic shocks. Specifically, the model features four nominal frictions, sticky prices, sticky wages, money in the utility function, and a cash-in-advance constraint on the wage bill of firms, and four sources of real rigidities, investment adjustment costs, variable capacity utilization, habit formation, and imperfect competition in product and factor markets. Aggregate fluctuations are driven by supply shocks, which take the form of stochastic variations in total factor productivity, and demand shocks stemming from exogenous innovations to the level of government purchases. Altig et al. (2003) and Christiano, Eichenbaum, and Evans (2003) argue that the model economy for which we seek to design optimal monetary policy can indeed explain the observed responses of inflation, real wages, nominal interest rates, money growth, output, investment,

\footnotetext{
${ }^{1}$ Examples of this line of research include Ireland (1997), Rotemberg and Woodford (1997), Woodford (2003), and Clarida, Galí, and Gertler (2000), among many others.
} 
consumption, labor productivity, and real profits to productivity and monetary shocks in the postwar United States. In this respect, the present paper aspires to be a step ahead in the research program of generating monetary policy evaluation that is of relevance for the actual practice of central banking.

In our quest for the optimal monetary policy scheme we restrict attention to what we call operational interest rate rules. By an operational interest-rate rule we mean an interest-rate rule that satisfies three requirements. First, it prescribes that the nominal interest rate is set as a function of a few readily observable macroeconomic variables. In the tradition of Taylor (1993), we focus on rules whereby the nominal interest rate depends on measures of inflation, aggregate activity, and possibly its own lag. Second, the operational rule must induce an equilibrium satisfying the zero lower bound on nominal interest rates. And third, operational rules must render the rational expectations equilibrium unique. This last restriction closes the door to expectations driven aggregate fluctuations.

The object that monetary policy aims to maximize in our study is the expectation of lifetime utility of the representative household conditional on a particular initial state of the economy. Our focus on a conditional welfare measure represents a fundamental departure from most existing normative evaluations of monetary policy, which rank policies based upon unconditional expectations of utility. ${ }^{2}$ As Kim et al. (2003) point out, unconditional welfare measures ignore the welfare effects of transitioning from a particular initial state to the stochastic steady state induced by the policy under consideration. Indeed, we document that under plausible initial conditions, conditional welfare measures can result in different rankings of policies than the more commonly used unconditional measure. This finding highlights the fact that transitional dynamics matter for policy evaluation.

In our welfare evaluations, we depart from the widespread practice in the neo-Keynesian literature on optimal monetary policy of limiting attention to models in which the nonstochastic steady state is undistorted. Most often, this approach involves assuming the existence of a battery of subsidies to production and employment aimed at eliminating the long-run distortions originating from monopolistic competition in factor and product markets. The efficiency of the deterministic steady-state allocation is assumed for purely computational reasons. For it allows the use of first-order approximation techniques to evaluate welfare accurately up to second order. ${ }^{3}$ This practice has two potential shortcomings. First, the instruments necessary to bring about an undistorted steady state (e.g., labor and output subsidies financed by lump-sum taxation) are empirically uncompelling. Second, it is ex ante not clear whether a policy that is optimal for an economy with an efficient steady state

\footnotetext{
${ }^{2}$ Exceptions are Kollmann (2003) and Schmitt-Grohé and Uribe (2004b).

${ }^{3}$ This simplification was pioneered by Rotemberg and Woodford (1997).
} 
will also be so for an economy where the instruments necessary to engineer the nondistorted steady state are unavailable. For these reasons, we refrain from making the efficient-steadystate assumption and instead work with a model whose steady state is distorted.

Departing from a model whose steady state is Pareto efficient has a number of important ramifications. One is that to obtain a second-order accurate measure of welfare it no longer suffices to approximate the equilibrium of the model up to first order. Instead, we obtain a second-order accurate approximation to welfare by solving the equilibrium of the model up to second order. Specifically, we use the methodology and computer code developed in SchmittGrohé and Uribe (2004c) to compute higher-order approximations to policy functions of dynamic, stochastic models. One advantage of this numerical strategy is that because it is based on perturbation arguments, it is particularly well suited to handle economies with a large number of state variables like the one studied in this paper.

In the neo-Keynesian literature, a recursive form for the equilibrium version of the pricesetting equation of firms (and workers if wages are sticky) is obtained by resorting to linear approximations at various stages of its derivation. The resulting expression is often referred to as the expectations augmented Phillips curve. For the reasons given above, such a linear expression is of no use for evaluating welfare in distorted economies. Therefore, in this paper we derive a recursive representation of the exact (nonlinear) Phillips curves for price and wage dynamics. A third consequence of working with an economy with long-run distortions and thus not being able to work with linearized versions of the equilibrium conditions of the model is the need to track the evolution of price and wage dispersion over time. This task gives rise to additional state variables summarizing the degree of relative price dispersion in the economy. We provide a recursive representation for the equilibrium law of motion of these state variables.

The results from our numerical work suggest that in the model economy we study, the optimal operational interest-rate rule takes the form of a real-interest-rate targeting rule. For it features an inflation coefficient close to unity, a mute response to output, no interest-rate smoothing, and is forward looking. The optimal rule satisfies the Taylor principle because the inflation coefficient is greater than unity albeit very close to 1 . Optimal monetary policy calls for significant inflation volatility. This result stands in contrast with those obtained in the related literature. The main element of the model driving the desirability of inflation volatility is indexation of nominal factor and product prices to 1-period lagged inflation. Under the alternative assumption of indexation to long-run inflation, the conventional result of the optimality of inflation stability reemerges. All of the above results are robust to a number of variations of the baseline model, including cashless economies, no habit formation, and economies with high costs of varying capacity utilization. 
The remainder of the paper is organized in six sections. Section 2 presents the theoretical economy and derives nonlinear recursive representations for the price and wage Phillips curves as well as for the state variables summarizing the degree of wage and price dispersion. Section 3 describes the calibration of the model and discusses the solution method. Section 4 provides intuition for the workings of the model by analyzing its dynamic response to supply and demand shocks under a simple Taylor-type interest-rate feedback rule. In section 5 we derive a second-order accurate measure of welfare conditional upon the current state of the economy. There, we also derive a second-order accurate consumption-based metric for the welfare differences between two alternative monetary policies. The core of the paper is contained in section 6 . It computes the optimal operational interest-rate rule and performs an extensive sensitivity analysis. Section 7 provides concluding remarks.

\section{The Model}

The skeleton of the model economy that we use for policy evaluation is the standard neoclassical growth model driven by productivity and government spending shocks. In addition the economy features four sources of nominal frictions and five real rigidities. The nominal frictions include price and wage stickiness à la Calvo (1983) and Yun (1996) with indexation to past inflation, and money demands by households and firms. The real rigidities originate from internal habit formation in consumption, monopolistic competition in factor and product markets, investment adjustment costs, and variable costs of adjusting capacity utilization.

To perform monetary policy evaluation, we are forced to approximate the equilibrium conditions of the economy to an order higher than linear. To this end, we derive the exact nonlinear recursive representation of the complete set of equilibrium conditions. Of particular interest is the recursive nonlinear representation of the equilibrium Phillips curves for prices and wages. These representations depart from most of the existing literature, which restricts attention to linear approximations to these functions. Another byproduct of deriving the exact nonlinear set of equilibrium conditions is the emergence of two state variables measuring the degree of price and wage dispersion in the economy induced by the sluggishness in the adjustment of nominal product and factor prices. We present a recursive representation of these state variables and track their dynamic behavior. 


\section{$2.1 \quad$ Households}

The economy is populated by a large representative family with a continuum of members. Each member is a worker. Consumption and hours worked are identical across family members. The household's preferences are defined over per capita consumption, $c_{t}$, per capita labor effort, $h_{t}$, and per capita holdings of real money balances, $m_{t}^{h}$, and are described by the utility function

$$
E_{0} \sum_{t=0}^{\infty} \beta^{t} U\left(c_{t}-b c_{t-1}, h_{t}, m_{t}^{h}\right)
$$

where $E_{t}$ denotes the mathematical expectations operator conditional on information available at time $t, \beta \in(0,1)$ represents a subjective discount factor, and $U$ is a period utility index assumed to be strictly increasing in its first and third arguments, strictly decreasing in its second argument, and strictly concave. Preferences display internal habit formation, measured by the parameter $b \in[0,1)$. The consumption good is assumed to be a composite made of a continuum of differentiated goods, $c_{i t}$ indexed by $i \in[0,1]$ via the aggregator

$$
c_{t}=\left[\int_{0}^{1} c_{i t}^{1-1 / \eta} d i\right]^{1 /(1-1 / \eta)}
$$

where the parameter $\eta>1$ denotes the intratemporal elasticity of substitution across different varieties of consumption goods.

For any given level of consumption of the composite good, purchases of each individual variety of goods $i \in[0,1]$ in period $t$ must solve the dual problem of minimizing total

expenditure, $\int_{0}^{1} P_{i t} c_{i t} d i$, subject to the aggregation constraint (2), where $P_{i t}$ denotes the nominal price of a good of variety $i$ at time $t$. The demand for goods of variety $i$ is then given by

$$
c_{i t}=\left(\frac{P_{i t}}{P_{t}}\right)^{-\eta} c_{t},
$$

where $P_{t}$ is a nominal price index given by

$$
P_{t} \equiv\left[\int_{0}^{1} P_{i t}^{1-\eta} d i\right]^{\frac{1}{1-\eta}}
$$

This price index has the property that the minimum cost of a bundle of intermediate goods yielding $c_{t}$ units of the composite good is given by $P_{t} c_{t}$.

Labor decisions are made by a central authority within the household, a union, which supplies labor monopolistically to a continuum of labor markets of measure 1 indexed by $j \in$ 
$[0,1] .{ }^{4}$ In each labor market $j$, the union faces a demand for labor given by $\left(W_{t}^{j} / W_{t}\right)^{-\tilde{\eta}} h_{t}^{d}$. Here $W_{t}^{j}$ denotes the nominal wage charged by the union in labor market $j$ at time $t, W_{t}$ is an index of nominal wages prevailing in the economy, and $h_{t}^{d}$ is a measure of aggregate labor demand by firms. We postpone a formal derivation of this labor demand function until we consider the firm's problem. In each particular labor market, the union takes $W_{t}$ and $h_{t}^{d}$ as exogenous. The case in which the union takes aggregate labor variables as endogenous can be interpreted as an environment with highly centralized labor unions. Higher-level labor organizations play an important role in some European and Latin American countries, but are less prominent in the United States. Given the wage charged in each labor market $j \in[0,1]$, the union is assumed to supply enough labor, $h_{t}^{j}$, to satisfy demand. That is,

$$
h_{t}^{j}=\left(\frac{w_{t}^{j}}{w_{t}}\right)^{-\tilde{\eta}} h_{t}^{d}
$$

where $w_{t}^{j} \equiv W_{t}^{j} / P_{t}$ and $w_{t} \equiv W_{t} / P_{t}$. In addition, the total number of hours allocated to the different labor markets must satisfy the resource constraint $h_{t}=\int_{0}^{1} h_{t}^{j} d j$. Combining this restriction with equation (5), we obtain

$$
h_{t}=h_{t}^{d} \int_{0}^{1}\left(\frac{w_{t}^{j}}{w_{t}}\right)^{-\tilde{\eta}} d j .
$$

The household is assumed to own physical capital, $k_{t}$, which accumulates according to the following law of motion

$$
k_{t+1}=(1-\delta) k_{t}+i_{t}\left[1-\mathcal{S}\left(\frac{i_{t}}{i_{t-1}}\right)\right]
$$

where $i_{t}$ denotes gross investment and $\delta$ is a parameter denoting the rate of depreciation of physical capital. The function $\mathcal{S}$ introduces investment adjustment costs and is assumed to satisfy $\mathcal{S}(1)=\mathcal{S}^{\prime}(1)=0$ and $\mathcal{S}^{\prime \prime}(1)>0$. These assumptions imply the absence of adjustment costs up to first order in the vicinity of the deterministic steady state. Owners of physical capital can control the intensity at which this factor is utilized. Formally, we let $u_{t}$ measure capacity utilization in period $t$. We assume that using the stock of capital with intensity $u_{t}$ entails a cost of $a\left(u_{t}\right) k_{t}$ units of the composite final good. The function $a$ is assumed to satisfy $a(1)=0$, and $a^{\prime}(1), a^{\prime \prime}(1)>0$. Both the specification of capital adjustment costs

\footnotetext{
${ }^{4}$ This setup departs slightly from most existing expositions of models with nominal wage inertia. It avoids the need to assume separability of preferences in leisure and consumption to ensure homogeneity of consumption across households.
} 
and capacity utilization costs are somewhat peculiar. More standard formulations assume that adjustment costs depend on the level of investment rather than on its growth rate, as is assumed here. Also, costs of capacity utilization typically take the form of a higher rate of depreciation of physical capital. The modeling choice here is guided by the need to fit the response of investment and capacity utilization to a monetary shock in the US economy. For further discussion of this point, see Christiano, Eichenbaum, and Evans (2003, section 6.1).

Households rent the capital stock to firms at the real rental rate $r_{t}^{k}$ per effective unit of capital. Thus, total income stemming from the rental of capital is given by $r_{t}^{k} u_{t} k_{t}$. The investment good is assumed to be a composite good made with the aggregator function (2). Thus, the demand for each intermediate good $i \in[0,1]$ for investment purposes, $i_{i t}$, is then given by $i_{i t}=i_{t}\left(P_{i t} / P_{t}\right)^{-\eta}$.

Households have access to a complete set of nominal state-contingent assets. Specifically, each period $t \geq 0$, consumers can purchase any desired state-contingent nominal payment $X_{t+1}^{h}$ in period $t+1$ at the dollar cost $E_{t} r_{t, t+1} X_{t+1}^{h}$. The variable $r_{t, t+1}$ denotes a stochastic nominal discount factor between periods $t$ and $t+1$. The household's period-by-period budget constraint is given by:

$$
E_{t} r_{t, t+1} x_{t+1}^{h}+c_{t}+i_{t}+m_{t}^{h}+a\left(u_{t}\right) k_{t}=\frac{x_{t}^{h}}{\pi_{t}}+h_{t}^{d} \int_{0}^{1} w_{t}^{j}\left(\frac{w_{t}^{j}}{w_{t}}\right)^{-\tilde{\eta}} d j+r_{t}^{k} u_{t} k_{t}+\phi_{t}-\tau_{t}+\frac{m_{t-1}^{h}}{\pi_{t}}
$$

The variable $x_{t}^{h} / \pi_{t} \equiv X_{t}^{h} / P_{t}$ denotes the real payoff in period $t$ of nominal state-contingent assets purchased in period $t-1$. The variable $\phi_{t}$ denotes profits received from the ownership of firms, $\tau_{t}$ denotes lump-sum taxes, and $\pi_{t} \equiv P_{t} / P_{t-1}$ denotes the gross rate of consumerprice inflation.

We introduce wage stickiness in the model by assuming that each period the household (or union) cannot set the nominal wage optimally in a fraction $\tilde{\alpha} \in[0,1$ ) of randomly chosen labor markets. In these markets, the wage rate is indexed to the previous period's consumerprice inflation according to the rule $W_{t}^{j}=W_{t-1}^{j} \pi_{t-1}^{\tilde{\chi}}$, where $\tilde{\chi}$ is a parameter measuring the degree of wage indexation. When $\tilde{\chi}$ equals 0 , there is no wage indexation. When $\tilde{\chi}$ equals 1 , there is full wage indexation to past consumer price inflation. In general, $\tilde{\chi}$ can take any value between 0 and 1 .

The household chooses processes for $c_{t}, h_{t}, x_{t+1}^{h}, w_{t}^{j}, k_{t+1}, i_{t}, m_{t}^{h}$, and $u_{t}$ so as to maximize the utility function (1) subject to (6)-(8), the wage stickiness friction, and a no-Ponzi-game constraint, taking as given the processes $w_{t}, r_{t}^{k}, h_{t}^{d}, r_{t, t+1}, \pi_{t}, \phi_{t}$, and $\tau_{t}$ and the initial conditions $x_{0}^{h}, k_{0}$, and $m_{-1}^{h}$. Of course, the household's optimal plan must satisfy constraints (6)-(8). In addition, letting $\beta^{t} \lambda_{t} w_{t} / \tilde{\mu}_{t}, \beta^{t} q_{t} \lambda_{t}$, and $\beta^{t} \lambda_{t}$ denote Lagrange multipliers 
associated with constraints (6), (7), and (8), respectively, the first-order conditions with respect to $c_{t}, x_{t+1}^{h}, h_{t}, k_{t+1}, i_{t}, u_{t}, m_{t}^{h}$, and $w_{t}^{j}$, in that order, are given by

$$
\begin{gathered}
U_{c}\left(c_{t}-b c_{t-1}, h_{t}, m_{t}^{h}\right)-b \beta E_{t} U_{c}\left(c_{t+1}-b c_{t}, h_{t+1}, m_{t+1}^{h}\right)=\lambda_{t}, \\
\lambda_{t} r_{t, t+1}=\beta \lambda_{t+1} \frac{P_{t}}{P_{t+1}} \\
-U_{h}\left(c_{t}-b c_{t-1}, h_{t}, m_{t}^{h}\right)=\frac{\lambda_{t} w_{t}}{\tilde{\mu}_{t}}, \\
\lambda_{t}=\lambda_{t} q_{t}\left[1-\mathcal{S}\left(\frac{i_{t}}{i_{t-1}}\right)-\left(\frac{i_{t}}{i_{t-1}}\right) \mathcal{S}^{\prime}\left(\frac{i_{t}}{i_{t-1}}\right)\right]+\beta E_{t} \lambda_{t+1} q_{t+1}\left(\frac{i_{t+1}}{i_{t}}\right)^{2} \mathcal{S}^{\prime}\left(\frac{i_{t+1}}{i_{t}}\right) \\
r_{t}^{k}=a^{\prime}\left(u_{t}\right) \\
\lambda_{t}=U_{m}\left(c_{t}-b c_{t-1}, h_{t}, m_{t}^{h}\right)+\beta E_{t} \frac{\lambda_{t+1}}{\pi_{t+1}} . \\
w_{t}^{j}=\left\{\begin{array}{cc}
\tilde{w}_{t} & \text { if } w_{t}^{j} \text { is set optimally in } t \\
w_{t-1}^{j} \pi_{t-1}^{\tilde{x}} / \pi_{t} & \text { otherwise }
\end{array}\right.
\end{gathered}
$$

where $\tilde{w}_{t}$ denotes the real wage prevailing in the $1-\tilde{\alpha}$ labor markets in which the union can set wages optimally in period $t$. Note that because the labor demand curve faced by the union is identical across all labor markets, and because the cost of supplying labor is the same for all markets, one can assume that wage rates and employment will be identical across all labor markets updating wages in a given period. The real wage $\tilde{w}_{t}$ must satisfy

$$
0=E_{t} \sum_{s=0}^{\infty}(\beta \tilde{\alpha})^{s} \lambda_{t+s}\left(\frac{\tilde{w}_{t}}{w_{t+s}}\right)^{-\tilde{\eta}} h_{t+s}^{d} \prod_{k=1}^{s}\left(\frac{\pi_{t+k}}{\pi_{t+k-1}^{\tilde{\tilde{x}}}}\right)^{\tilde{\eta}}\left[\frac{\tilde{\eta}-1}{\tilde{\eta}} \frac{\tilde{w}_{t}}{\prod_{k=1}^{s}\left(\frac{\pi_{t+k}}{\pi_{t+k-1}^{t}}\right)}-\frac{w_{t+s}}{\tilde{\mu}_{t+s}}\right] .
$$

This expression states that in labor markets in which the wage rate is reoptimized in period $t$, the real wage is set so as to equate the union's future expected average marginal revenue to the average marginal cost of supplying labor. The union's marginal revenue $s$ periods after its last wage reoptimization is given by $\frac{\tilde{\eta}-1}{\tilde{\eta}} \tilde{w}_{t} \prod_{k=1}^{s}\left(\frac{\pi_{t+k-1}^{\tilde{\chi}}}{\pi_{t+k}}\right)$. Here, $\tilde{\eta} /(\tilde{\eta}-1)$ represents the markup of wages over marginal cost of labor that would prevail in the absence of wage stickiness. The third factor in the expression for marginal revenue reflects the fact that as time goes by without a chance to reoptimize, the real wage declines as the price level increases when wages are imperfectly indexed to past inflation. In turn, the marginal cost 
of supplying labor is given by the marginal rate of substitution between consumption and leisure, or $\frac{-U_{h t+s}}{\lambda_{t+s}}=\frac{w_{t+s}}{\tilde{\mu}_{t+s}}$. The variable $\tilde{\mu}_{t}$ is a wedge between the disutility of labor and the average real wage prevailing in the economy. Thus, $\tilde{\mu}_{t}$ can be interpreted as the average markup that unions impose on the labor market. The weights used to compute averages are decreasing in time and increasing in the amount of labor supplied to the market.

We wish to write the wage-setting equation in recursive form. To this end, define

$$
f_{t}^{1}=E_{t} \sum_{s=0}^{\infty}(\beta \tilde{\alpha})^{s} \lambda_{t+s}\left(\frac{w_{t+s}}{\tilde{w}_{t}}\right)^{\tilde{\eta}} h_{t+s}^{d} \prod_{k=1}^{s}\left(\frac{\pi_{t+k}}{\pi_{t+k-1}^{\tilde{\chi}}}\right)^{\tilde{\eta}-1}
$$

and

$$
f_{t}^{2}=\tilde{w}_{t}^{-\tilde{\eta}} E_{t} \sum_{s=0}^{\infty}(\beta \tilde{\alpha})^{s} \frac{\lambda_{t+s}}{\tilde{\mu}_{t+s}} w_{t+s}^{1+\tilde{\eta}} h_{t+s}^{d} \prod_{k=1}^{s}\left(\frac{\pi_{t+k}}{\pi_{t+k-1}^{\tilde{\chi}}}\right)^{\tilde{\eta}} .
$$

One can express $f_{t}^{1}$ and $f_{t}^{2}$ recursively as

$$
\begin{aligned}
& f_{t}^{1}=\lambda_{t}\left(\frac{w_{t}}{\tilde{w}_{t}}\right)^{\tilde{\eta}} h_{t}^{d}+\tilde{\alpha} \beta E_{t}\left(\frac{\pi_{t+1}}{\pi_{t}^{\tilde{\chi}}}\right)^{\tilde{\eta}-1}\left(\frac{\tilde{w}_{t+1}}{\tilde{w}_{t}}\right)^{\tilde{\eta}} f_{t+1}^{1}, \\
& f_{t}^{2}=\frac{\lambda_{t}}{\tilde{\mu}_{t}} w_{t}\left(\frac{w_{t}}{\tilde{w}_{t}}\right)^{\tilde{\eta}} h_{t}^{d}+\tilde{\alpha} \beta E_{t}\left(\frac{\pi_{t+1}}{\pi_{t}^{\tilde{\chi}}}\right)^{\tilde{\eta}}\left(\frac{\tilde{w}_{t+1}}{\tilde{w}_{t}}\right)^{\tilde{\eta}} f_{t+1}^{2} .
\end{aligned}
$$

With these definitions at hand, the wage-setting equation becomes

$$
0=(1-\tilde{\eta}) \tilde{w}_{t} f_{t}^{1}+\tilde{\eta} f_{t}^{2}
$$

The household's optimality conditions imply a liquidity function featuring a negative relation between real balances and the short-term nominal interest rate. To see this, we first note that the absence of arbitrage opportunities in financial markets requires that $R_{t}$ be equal to the reciprocal of the price in period $t$ of a nominal security that pays one unit of currency in every state of period $t+1$. Formally, $1 / R_{t}=E_{t} r_{t, t+1}$. This relation together with the household's optimality condition (10) implies that

$$
\lambda_{t}=\beta R_{t} E_{t} \frac{\lambda_{t+1}}{\pi_{t+1}}
$$

which is a standard Euler equation for pricing nominally risk-free assets. Now combining this expression with equations (9) and (15) we obtain

$$
\frac{U_{m}\left(c_{t}-b c_{t-1}, h_{t}, m_{t}^{h}\right)}{U_{c}\left(c_{t}-b c_{t-1}, h_{t}, m_{t}^{h}\right)-b \beta E_{t} U_{c}\left(c_{t+1}-b c_{t}, h_{t+1}, m_{t+1}^{h}\right)}=1-\frac{1}{R_{t}}
$$


The right-hand side of this expression represents the opportunity cost of holding money, which is an increasing function of the nominal interest rate. The left-hand side is the marginal rate of substitution between consumption and real money balances. Note that the presence of internal habit formation implies that the demand for money depends not only on current but also past and future expected consumption. In addition, if preferences are nonseparable in leisure and either consumption or real balances, then hours worked will also feature in the liquidity preference function.

\section{$2.2 \quad$ Firms}

Each variety of final goods is produced by a single firm in a monopolistically competitive environment. Each firm $i \in[0,1]$ produces output using as factor inputs capital services, $k_{i t}$, and labor services, $h_{i t}$. The production technology is given by

$$
z_{t} F\left(k_{i t}, h_{i t}\right)-\psi
$$

where the function $F$ is assumed to be homogenous of degree one, concave, and strictly increasing in both arguments. The variable $z_{t}$ denotes an aggregate, exogenous, and stochastic productivity shock. The parameter $\psi>0$ introduces fixed costs of operating a firm in each period. It implies that the production function exhibits increasing returns to scale. We model fixed costs to ensure a realistic profit-to-output ratio in steady state.

Aggregate demand for good $i$, which we denote by $y_{i t}$, is given by

$$
y_{i t}=\left(P_{i t} / P_{t}\right)^{-\eta} y_{t}
$$

where

$$
y_{t} \equiv c_{t}+i_{t}+g_{t}+a\left(u_{t}\right) k_{t}
$$

denotes aggregate absorption. The variable $g_{t}$ denotes government consumption of the composite good in period $t$.

We rationalize a demand for money by firms by imposing that wage payments are subject to a cash-in-advance constraint of the form:

$$
m_{i t}^{f} \geq \nu w_{t} h_{i t}
$$

where $m_{i t}^{f}$ denotes the demand for real money balances by firm $i$ in period $t$ and $\nu \geq 0$ is a parameter indicating the fraction of the wage bill that must be backed with monetary assets. 
The period-by-period budget constraint of firm $i$ is given by

$$
E_{t} r_{t, t+1} x_{i t+1}^{f}+m_{i t}^{f}+r_{t}^{k} k_{i t}+w_{t} h_{i t}+\phi_{i t}=\frac{x_{i t}^{f}+m_{i t-1}^{f}}{\pi_{t}}+\left(\frac{P_{i t}}{P_{t}}\right)^{1-\eta} y_{t},
$$

where $E_{t} r_{t, t+1} x_{i t+1}^{f}$ denotes the total real cost of one-period state-contingent assets that the firm purchases in period $t$ in terms of the composite good. The variable $\phi_{i t}$ denotes real dividend payments that firm $i$ makes to households in period $t$. Implicit in this specification of the firm's budget constraint is the assumption that firms rent capital services from a centralized market. ${ }^{5}$ We assume that the firm must satisfy demand at the posted price. Formally, we impose

$$
z_{t} F\left(k_{i t}, h_{i t}\right)-\psi \geq\left(\frac{P_{i t}}{P_{t}}\right)^{-\eta} y_{t} .
$$

The objective of the firm is to choose contingent plans for $P_{i t}, h_{i t}, k_{i t}, x_{i t+1}^{f}$, and $m_{i t}^{f}$ so as to maximize the present discounted value of dividend payments, given by

$$
E_{t} \sum_{s=0}^{\infty} r_{t, t+s} P_{t+s} \phi_{i t+s}
$$

where $r_{t, t+s} \equiv \prod_{k=1}^{s} r_{t+k-1, t+k}$, for $s \geq 1$, denotes the stochastic nominal discount factor between $t$ and $t+s$, and $r_{t, t} \equiv 1$. Firms are assumed to be subject to a borrowing constraint that prevents them from engaging in Ponzi games.

Throughout our analysis, we will focus on equilibria featuring a strictly positive nominal interest rate. This implies that the cash-in-advance constraint (21) will always bind. Then, letting $r_{t, t+s} P_{t+s} \mathrm{mc}_{i t+s}$ be the Lagrange multiplier associated with constraint (22), the firstorder conditions of the firm's maximization problem with respect to capital and labor services are, respectively,

$$
\mathrm{mc}_{i t} z_{t} F_{h}\left(k_{i t}, h_{i t}\right)=w_{t}\left[1+\nu \frac{R_{t}-1}{R_{t}}\right]
$$

and

$$
\mathrm{mc}_{i t} z_{t} F_{k}\left(k_{i t}, h_{i t}\right)=r_{t}^{k} .
$$

It is clear from these optimality conditions that the presence of a working-capital requirement introduces a financial cost of labor that is increasing in the nominal interest rate. We note

\footnotetext{
${ }^{5}$ This is a common assumption in the related literature (e.g., Christiano et al., 2003; Kollmann, 2003; Carlstrom and Fuerst, 2003; and Rotemberg and Woodford, 1992). A polar assumption is that capital is sector specific, as in Woodford (2003, chapter 5.3) and Sveen and Weinke (2003). Both assumptions are clearly extreme. A more realistic treatment of investment dynamics would incorporate a mix of firm-specific and homogeneous capital.
} 
also that because all firms face the same factor prices and because they all have access to the same production technology with the function $F$ being linearly homogeneous, marginal costs, $\mathrm{mc}_{i t}$, are identical across firms. Indeed, because the above first-order conditions hold for all firms independently of whether they are allowed to reset prices optimally or not, marginal costs are identical across all firms in the economy.

Clearly, because $r_{t, t+s}$ represents both the firm's stochastic discount factor and the market pricing kernel for financial assets, and because the firm's objective function is linear in asset holdings, it follows that any asset accumulation plan of the firm satisfying the no-Ponzi constraint is optimal. Suppose, without loss of generality, that the firm manages its portfolio so as to ensure that its financial position at the beginning of each period is nil. Formally, assume that $x_{i t+1}^{f}+m_{i t}^{f}=0$ at all dates and states. Note that this financial strategy makes $x_{i t+1}^{f}$ state-noncontingent. In this case, distributed dividends take the form

$$
\phi_{i t}=\left(\frac{P_{i t}}{P_{t}}\right)^{1-\eta} y_{t}-r_{t}^{k} k_{i t}-w_{t} h_{i t}-\left(1-R_{t}^{-1}\right) m_{i t}^{f}
$$

For this expression to hold in period zero, we impose the initial condition $x_{i 0}^{f}+m_{i-1}^{f}=0$. The last term on the right-hand side of this expression represents the firm's financial costs associated with the cash-in-advance constraint on wages. This financial cost is increasing in the opportunity cost of holding money, $1-R_{t}^{-1}$, which is an increasing function of the short-term nominal interest rate $R_{t}$.

Prices are assumed to be sticky à la Calvo (1983) and Yun (1996). Specifically, each period $t \geq 0$ a fraction $\alpha \in[0,1)$ of randomly picked firms is not allowed to optimally set the nominal price of the good they produce. Instead, these firms index their prices to past inflation according to the rule $P_{i t}=P_{i t-1} \pi_{t-1}^{\chi}$. The interpretation of the parameter $\chi$ is the same as that of its wage counterpart $\tilde{\chi}$. The remaining $1-\alpha$ firms choose prices optimally. Consider the price-setting problem faced by a firm that gets to reoptimize the price in period $t$. This price, which we denote by $\tilde{P}_{t}$, is set so as to maximize the expected present discounted value of profits. That is, $\tilde{P}_{t}$ maximizes the following Lagrangian:

$$
\begin{aligned}
\mathcal{L}= & E_{t} \sum_{s=0}^{\infty} r_{t, t+s} P_{t+s} \alpha^{s}\left\{\left(\frac{\tilde{P}_{t}}{P_{t}}\right)^{1-\eta} \prod_{k=1}^{s}\left(\frac{\pi_{t+k-1}^{\chi}}{\pi_{t+k}}\right)^{1-\eta} y_{t+s}-r_{t+s}^{k} k_{i t+s}-w_{t+s} h_{i t+s}\left[1+\nu\left(1-R_{t+s}^{-1}\right)\right]\right. \\
& \left.+\mathrm{mc}_{i t+s}\left[z_{t+s} F\left(k_{i t+s}, h_{i t+s}\right)-\psi-\left(\frac{\tilde{P}_{t}}{P_{t}}\right)^{-\eta} \prod_{k=1}^{s}\left(\frac{\pi_{t+k-1}^{\chi}}{\pi_{t+k}}\right)^{-\eta} y_{t+s}\right]\right\} .
\end{aligned}
$$


The first-order condition with respect to $\tilde{P}_{t}$ is

$$
E_{t} \sum_{s=0}^{\infty} r_{t, t+s} P_{t+s} \alpha^{s}\left(\frac{\tilde{P}_{t}}{P_{t}}\right)^{-\eta} \prod_{k=1}^{s}\left(\frac{\pi_{t+k-1}^{\chi}}{\pi_{t+k}}\right)^{-\eta} y_{t+s}\left[\frac{\eta-1}{\eta}\left(\frac{\tilde{P}_{t}}{P_{t}}\right) \prod_{k=1}^{s}\left(\frac{\pi_{t+k-1}^{\chi}}{\pi_{t+k}}\right)-m c_{i t+s}\right]=0 .
$$

According to this expression, optimizing firms set nominal prices so as to equate average future expected marginal revenues to average future expected marginal costs. The weights used in calculating these averages are decreasing with time and increasing in the size of the demand for the good produce by the firm. Under flexible prices $(\alpha=0)$, the above optimality condition reduces to a static relation equating marginal costs to marginal revenues period by period.

It will prove useful to express this first-order condition recursively. To that end, let

$$
x_{t}^{1} \equiv E_{t} \sum_{s=0}^{\infty} r_{t, t+s} \alpha^{s} y_{t+s} m c_{i t+s}\left(\frac{\tilde{P}_{t}}{P_{t}}\right)^{-\eta-1} \prod_{k=1}^{s}\left(\frac{\pi_{t+k-1}^{\chi}}{\pi_{t+k}^{(1+\eta) / \eta}}\right)^{-\eta}
$$

and

$$
x_{t}^{2} \equiv E_{t} \sum_{s=0}^{\infty} r_{t, t+s} \alpha^{s} y_{t+s}\left(\frac{\tilde{P}_{t}}{P_{t}}\right)^{-\eta} \prod_{k=1}^{s}\left(\frac{\pi_{t+k-1}^{\chi}}{\pi_{t+k}^{\eta /(\eta-1)}}\right)^{1-\eta}
$$

Express $x_{t}^{1}$ and $x_{t}^{2}$ recursively as

$$
\begin{gathered}
x_{t}^{1}=y_{t} \mathrm{mc}_{t} \tilde{p}_{t}^{-\eta-1}+\alpha \beta E_{t} \frac{\lambda_{t+1}}{\lambda_{t}}\left(\tilde{p}_{t} / \tilde{p}_{t+1}\right)^{-\eta-1}\left(\frac{\pi_{t}^{\chi}}{\pi_{t+1}}\right)^{-\eta} x_{t+1}^{1}, \\
x_{t}^{2}=y_{t} \tilde{p}_{t}^{-\eta}+\alpha \beta E_{t} \frac{\lambda_{t+1}}{\lambda_{t}}\left(\frac{\pi_{t}^{\chi}}{\pi_{t+1}}\right)^{1-\eta}\left(\frac{\tilde{p}_{t}}{\tilde{p}_{t+1}}\right)^{-\eta} x_{t+1}^{2} .
\end{gathered}
$$

Then we can write the first-order condition with respect to $\tilde{P}_{t}$ as

$$
\eta x_{t}^{1}=(\eta-1) x_{t}^{2}
$$

The labor input used by firm $i \in[0,1]$, denoted $h_{i t}$, is assumed to be a composite made of a continuum of differentiated labor services, $h_{i t}^{j}$ indexed by $j \in[0,1]$. Formally,

$$
h_{i t}=\left[\int_{0}^{1} h_{i t}^{j 1-1 / \tilde{\eta}} d j\right]^{1 /(1-1 / \tilde{\eta})}
$$

where the parameter $\tilde{\eta}>1$ denotes the intratemporal elasticity of substitution across dif- 
ferent types of activities. For any given level of $h_{i t}$, the demand for each variety of labor $j \in[0,1]$ in period $t$ must solve the dual problem of minimizing total labor cost, $\int_{0}^{1} W_{t}^{j} h_{i t}^{j} d j$, subject to the aggregation constraint (30), where $W_{t}^{j}$ denotes the nominal wage rate paid to labor of variety $j$ at time $t$. The optimal demand for labor of type $j$ is then given by

$$
h_{i t}^{j}=\left(\frac{W_{t}^{j}}{W_{t}}\right)^{-\tilde{\eta}} h_{i t},
$$

where $W_{t}$ is a nominal wage index given by

$$
W_{t} \equiv\left[\int_{0}^{1} W_{t}^{j^{1-\tilde{\eta}}} d j\right]^{\frac{1}{1-\tilde{\eta}}} .
$$

This wage index has the property that the minimum cost of a bundle of intermediate labor inputs yielding $h_{i t}$ units of the composite labor input is given by $W_{t} h_{i t}$.

\subsection{The Government}

Government expenditure is financed via lump-sum taxes and seignorage

$$
g_{t}=\tau_{t}+m_{t}-\frac{m_{t-1}}{\pi_{t}}
$$

where $m_{t}=m_{t}^{h}+\int_{0}^{1} m_{i t}^{f} d i$ denotes real money balances and $g_{t}$ denotes per capita government spending on a composite good produced via the aggregator function given in equation (2). We assume that the government minimizes the cost of producing $g_{t}$. Thus, we have that the public demand for a particular variety $i \in[0,1]$ of differentiated goods, $g_{i t}$, is given by $g_{i t}=\left(P_{i t} / P_{t}\right)^{-\eta} g_{t}$.

Monetary policy is given by an interest-rate feedback rule of the form

$$
\hat{R}_{t}=\alpha_{\pi} E_{t} \hat{\pi}_{t-i}+\alpha_{y} E_{t} \hat{y}_{t-i}+\alpha_{R} \hat{R}_{t-1},
$$

where a hat over a variable denotes the log-deviation of that variable from its deterministic steady-state level (i.e., for any $x_{t}, \hat{x}_{t} \equiv \ln \left(x_{t} / x\right)$, where $x$ denotes the non-stochastic steadystate value of $\left.x_{t}\right)$. The parameter $i$ allows for backward-looking rules $(i=1)$, current-looking rules $(i=0)$, and forward-looking rules $(i=-1)$. We assume that in period 0 the government chooses the policy quadruple $\left(\alpha_{\pi}, \alpha_{y}, \alpha_{R}, i\right)$ so as to maximize the lifetime utility of the representative household. The government is assumed to be endowed with a commitment technology that allows it to maintain throughout time the policy decision it makes in period 
0. As a result, the announced policy enjoys full credibility on the part of the private sector.

The family of interest rate feedback rules defined by (33) has the property of being easily implementable. For all of the variables featured in the rule are generally available macroeconomic indicators. We note that the type of monetary policy rules that are typically analyzed in the related literature require no less information on the part of the policymaker than the feedback rule given in equation (33). In effect, the rules most commonly studied feature an output gap measure defined as deviations of output from the level that would obtain in the absence of nominal rigidities. Computing the flexible-price level of aggregate activity requires the policymaker to know not just the deterministic steady state of the economy, but also the joint distribution of all the shocks driving the economy and the current realizations of such shocks.

\subsection{Aggregation and Equilibrium}

We limit attention to a symmetric equilibrium in which all firms that get to change their price optimally at a given time indeed choose the same price. It then follows from (4) that the aggregate price index can be written as $P_{t}^{1-\eta}=\alpha\left(P_{t-1} \pi_{t-1}^{\chi}\right)^{1-\eta}+(1-\alpha) \tilde{P}_{t}^{1-\eta}$. Dividing this expression through by $P_{t}^{1-\eta}$ one obtains

$$
1=\alpha \pi_{t}^{\eta-1} \pi_{t-1}^{\chi(1-\eta)}+(1-\alpha) \tilde{p}_{t}^{1-\eta}
$$

\subsubsection{Market Clearing in the Final Goods Market}

Naturally, the set of equilibrium conditions includes a resource constraint. Such a restriction is typically of the type $z_{t} F\left(k_{t}, h_{t}\right)-\psi=c_{t}+i_{t}+g_{t}+a\left(u_{t}\right) k_{t}$. In the present model, however, this restriction is not valid. This is because the model implies relative price dispersion across varieties. This price dispersion, which is induced by the assumed nature of price stickiness, is inefficient and entails output loss. To see this, consider the following expression stating that supply must equal demand at the firm level:

$$
z_{t} F\left(k_{i t}, h_{i t}\right)-\psi=\left(c_{t}+i_{t}+g_{t}+a\left(u_{t}\right) k_{t}\right)\left(\frac{P_{i t}}{P_{t}}\right)^{-\eta} .
$$

Integrating over all firms and taking into account that (a) the capital-labor ratio is common across firms, (b) that the aggregate demand for the composite labor input, $h_{t}^{d}$, satisfies

$$
h_{t}^{d}=\int_{0}^{1} h_{i t} d i
$$


and that (c) the aggregate effective level of capital, $u_{t} k_{t}$ satisfies

$$
u_{t} k_{t}=\int_{0}^{1} k_{i t} d i
$$

we obtain

$$
h_{t}^{d} z_{t} F\left(\frac{u_{t} k_{t}}{h_{t}^{d}}, 1\right)-\psi=\left(c_{t}+i_{t}+g_{t}+a\left(u_{t}\right) k_{t}\right) \int_{0}^{1}\left(\frac{P_{i t}}{P_{t}}\right)^{-\eta} d i .
$$

Let $s_{t} \equiv \int_{0}^{1}\left(\frac{P_{i t}}{P_{t}}\right)^{-\eta} d i$. Then we have

$$
\begin{aligned}
s_{t} & =\int_{0}^{1}\left(\frac{P_{i t}}{P_{t}}\right)^{-\eta} d i \\
& =(1-\alpha)\left(\frac{\tilde{P}_{t}}{P_{t}}\right)^{-\eta}+(1-\alpha) \alpha\left(\frac{\tilde{P}_{t-1} \pi_{t-1}^{\chi}}{P_{t}}\right)^{-\eta}+(1-\alpha) \alpha^{2}\left(\frac{\tilde{P}_{t-2} \pi_{t-1}^{\chi} \pi_{t-2}^{\chi}}{P_{t}}\right)^{-\eta}+\ldots \\
& =(1-\alpha) \sum_{j=0}^{\infty} \alpha^{j}\left(\frac{\tilde{P}_{t-j} \prod_{s=1}^{j} \pi_{t-j-1+s}^{\chi}}{P_{t}}\right)^{-\eta} \\
& =(1-\alpha) \tilde{p}_{t}^{-\eta}+\alpha\left(\frac{\pi_{t}}{\pi_{t-1}^{\chi}}\right)^{\eta} s_{t-1} .
\end{aligned}
$$

Summarizing, the resource constraint in the present model is given by the following two expressions

$$
\begin{gathered}
z_{t} F\left(u_{t} k_{t}, h_{t}^{d}\right)-\psi=\left(c_{t}+i_{t}+g_{t}+a\left(u_{t}\right) k_{t}\right) s_{t} \\
s_{t}=(1-\alpha) \tilde{p}_{t}^{-\eta}+\alpha\left(\frac{\pi_{t}}{\pi_{t-1}^{\chi}}\right)^{\eta} s_{t-1},
\end{gathered}
$$

with $s_{-1}$ given. The state variable $s_{t}$ summarizes the resource costs induced by the inefficient price dispersion featured in the Calvo model in equilibrium. Three observations are in order about the price dispersion measure $s_{t}$. First, $s_{t}$ is bounded below by 1 . That is, price dispersion is always a costly distortion in this model. To see that $s_{t}$ is bounded below by 1 , let $v_{i t} \equiv\left(P_{i t} / P_{t}\right)^{1-\eta}$. It follows from the definition of the price index given in equation (4) that $\left[\int_{0}^{1} v_{i t}\right]^{\eta /(\eta-1)}=1$. Also, by definition we have $s_{t}=\int_{0}^{1} v_{i t}^{\eta /(\eta-1)}$. Then, taking into account that $\eta /(\eta-1)>1$, Jensen's inequality implies that $1=\left[\int_{0}^{1} v_{i t}\right]^{\eta /(\eta-1)} \leq \int_{0}^{1} v_{i t}^{\eta /(\eta-1)}=s_{t}$. Second, in an economy where the non-stochastic level of inflation is nil (i.e., when $\pi=1$ ) or where prices are fully indexed to any variable $\omega_{t}$ with the property that its deterministic steady-state value equals the deterministic steady-state value of inflation (i.e., $\omega=\pi$ ), the variable $s_{t}$ follows, up to first order, the univariate autoregressive process $\hat{s}_{t}=\alpha \hat{s}_{t-1}$. In these cases, the price dispersion measure $s_{t}$ has no first-order real consequences for the stationary 
distribution of any endogenous variable of the model. This means that studies that restrict attention to linear approximations to the equilibrium conditions are justified to ignore the variable $s_{t}$ if the model features no price dispersion in the deterministic steady state. But $s_{t}$ matters up to first order when the deterministic steady state features movements in relative prices across goods varieties. More importantly, the price dispersion variable $s_{t}$ must be taken into account if one is interested in higher-order approximations to the equilibrium conditions even if relative prices are stable in the deterministic steady state. Omitting $s_{t}$ in higher-order expansions would amount to leaving out certain higher-order terms while including others. Finally, when prices are fully flexible, $\alpha=0$, we have that $\tilde{p}_{t}=1$ and thus $s_{t}=1$. (Obviously, in a flexible-price equilibrium there is no price dispersion across varieties.)

As discussed above, equilibrium marginal costs and capital-labor ratios are identical across firms. Therefore, one can aggregate the firm's optimality conditions with respect to labor and capital, equations (23) and (24), as

$$
\mathrm{mc}_{t} z_{t} F_{h}\left(u_{t} k_{t}, h_{t}^{d}\right)=w_{t}\left[1+\nu \frac{R_{t}-1}{R_{t}}\right]
$$

and

$$
\mathrm{mc}_{t} z_{t} F_{k}\left(u_{t} k_{t}, h_{t}^{d}\right)=r_{t}^{k}
$$

\subsubsection{Market Clearing in the Labor Market}

It follows from equation (31) that the aggregate demand for labor of type $j \in[0,1]$, which we denote by $h_{t}^{j} \equiv \int_{0}^{1} h_{i t}^{j} d i$, is given by

$$
h_{t}^{j}=\left(\frac{W_{t}^{j}}{W_{t}}\right)^{-\tilde{\eta}} h_{t}^{d}
$$

where $h_{t}^{d} \equiv \int_{0}^{1} h_{i t} d i$ denotes the aggregate demand for the composite labor input. Taking into account that at any point in time the nominal wage rate is identical across all labor markets at which wages are allowed to change optimally, we have that labor demand in each of those markets is

$$
\tilde{h}_{t}=\left(\frac{\tilde{w}_{t}}{w_{t}}\right)^{-\tilde{\eta}} h_{t}^{d}
$$


Combining this expression with equation (39), describing the demand for labor of type $j \in[0,1]$, and with the time constraint (6), which must hold with equality, we can write

$$
h_{t}=(1-\tilde{\alpha}) h_{t}^{d} \sum_{s=0}^{\infty} \tilde{\alpha}^{s}\left(\frac{\tilde{W}_{t-s} \prod_{k=1}^{s} \pi_{t+k-s-1}^{\tilde{\chi}}}{W_{t}}\right)^{-\tilde{\eta}}
$$

Let $\tilde{s}_{t} \equiv(1-\tilde{\alpha}) \sum_{s=0}^{\infty} \tilde{\alpha}^{s}\left(\frac{\tilde{W}_{t-s} \prod_{k=1}^{s} \pi_{t+k-s-1}^{\tilde{\chi}}}{W_{t}}\right)^{-\tilde{\eta}}$. The variable $\tilde{s}_{t}$ measures the degree of wage dispersion across different types of labor. The above expression can be written as

$$
h_{t}=\tilde{s}_{t} h_{t}^{d}
$$

The state variable $\tilde{s}_{t}$ evolves over time according to

$$
\tilde{s}_{t}=(1-\tilde{\alpha})\left(\frac{\tilde{w}_{t}}{w_{t}}\right)^{-\tilde{\eta}}+\tilde{\alpha}\left(\frac{w_{t-1}}{w_{t}}\right)^{-\tilde{\eta}}\left(\frac{\pi_{t}}{\pi_{t-1}^{\tilde{\chi}}}\right)^{\tilde{\eta}} \tilde{s}_{t-1}
$$

We note that because all job varieties are ex-ante identical, any wage dispersion is inefficient. This is reflected in the fact that $\tilde{s}_{t}$ is bounded below by 1 . The proof of this statement is identical to that offered earlier for $s_{t}$. To see this, note that $\tilde{s}_{t}$ can be written as $\tilde{s}_{t}=\int_{0}^{1}\left(\frac{W_{i t}}{W_{t}}\right)^{-\tilde{\eta}} d i$. This inefficiency introduces a wedge that makes the number of hours supplied to the market, $h_{t}$, larger than the number of productive units of labor input, $h_{t}^{d}$. In an environment without long-run wage dispersion, the dead-weight loss created by wage dispersion is nil up to first order. Formally, a first-order approximation of the law of motion of $\tilde{s}_{t}$ yields a univariate autoregressive process of the form $\hat{\tilde{s}}_{t}=\tilde{\alpha} \hat{\tilde{s}}_{t-1}$, as long as there is no wage dispersion in the deterministic steady state. When wages are fully flexible, $\tilde{\alpha}=0$, wage dispersion disappears, and thus $\tilde{s}_{t}$ equals 1 .

It follows from our definition of the wage index given in equation (32) that in equilibrium the real wage rate must satisfy

$$
w_{t}^{1-\tilde{\eta}}=(1-\tilde{\alpha}) \tilde{w}_{t}^{1-\tilde{\eta}}+\tilde{\alpha} w_{t-1}^{1-\tilde{\eta}}\left(\frac{\pi_{t-1}^{\tilde{\chi}}}{\pi_{t}}\right)^{1-\tilde{\eta}}
$$

A stationary competitive equilibrium is a set of stationary processes $c_{t}, h_{t}, i_{t}, k_{t+1}, m_{t}^{h}$, $\lambda_{t}, R_{t}, \pi_{t}, w_{t}, \tilde{\mu}_{t}, q_{t}, r_{t}^{k}, u_{t}, f_{t}^{1}, f_{t}^{2}, \tilde{w}_{t}, h_{t}^{d}, \tilde{h}_{t}, y_{t}, \mathrm{mc}_{t}, x_{t}^{1}, x_{t}^{2}, \tilde{p}_{t}, s_{t}, \tilde{s}_{t}$ satisfying (7), (9), (11)(20), (27)-(29), (33)-(38), and (40)-(43), given exogenous stochastic processes $\left\{g_{t}, z_{t}\right\}_{t=0}^{\infty}$ and initial conditions $c_{-1}, w_{-1}, s_{-1}, \tilde{s}_{-1}, \pi_{-1}, k_{0}, i_{-1}, R_{-1}$, and, in the case of backward-looking interest-rate rules, $y_{-1}$. 


\section{Solution Method, Functional Forms, and Calibration}

The above set of equilibrium conditions can be written as

$$
E_{t} f\left(y_{t+1}, y_{t}, x_{t+1}, x_{t}\right)=0
$$

where the vector $x_{t}$ contains the predetermined, or state variables and is of size $n_{x}$, and the vector $y_{t}$ contains the nonpredetermined variables of the model and is of size $n_{y}$. Let $n=n_{x}+n_{y}$. The state vector $x_{t}$ can be partitioned as $x_{t}=\left[x_{t}^{1} ; x_{t}^{2}\right]^{\prime}$. The vector $x_{t}^{1}$ consists of endogenous predetermined state variables and the vector $x_{t}^{2}$ consists of exogenous state variables. Specifically, we assume that $x_{t}^{2}$ follows the exogenous stochastic process given by

$$
x_{t+1}^{2}=\Lambda x_{t}^{2}+\tilde{\eta}_{\epsilon} \sigma \epsilon_{t+1},
$$

where both the vector $x_{t}^{2}$ and the innovation $\epsilon_{t}$ are of order $n_{\epsilon} \times 1$. The vector $\epsilon_{t}$ is assumed to have a bounded support and to be independently and identically distributed, with mean zero and variance/covariance matrix $I$. The scalar $\sigma \geq 0$ and the $n_{\epsilon} \times n_{\epsilon}$ matrix $\tilde{\eta}_{\epsilon}$ are known parameters. All eigenvalues of the matrix $\Lambda$ are assumed to have modulus less than one. The solution to the model given in equation (44) is of the form:

$$
y_{t}=g\left(x_{t}, \sigma\right)
$$

and

$$
x_{t+1}=h\left(x_{t}, \sigma\right)+\eta_{\epsilon} \sigma \epsilon_{t+1},
$$

where $g$ maps $R^{n_{x}} \times R^{+}$into $R^{n_{y}}$ and $h$ maps $R^{n_{x}} \times R^{+}$into $R^{n_{x}}$. The matrix $\eta_{\epsilon}$ is of order $n_{x} \times n_{\epsilon}$ and is given by

$$
\eta_{\epsilon}=\left[\begin{array}{c}
\emptyset \\
\tilde{\eta}_{\epsilon}
\end{array}\right] .
$$

We use the methodology and computer code developed in Schmitt-Grohé and Uribe (2004c) to compute a second-order approximation of the functions $g$ and $h$ around the non-stochastic steady state, $x_{t}=x$ and $\sigma=0 .{ }^{6}$ The deterministic steady state of the model, $(x, y)$, is the solution to the system $f(y, y, x, x)=0$.

\footnotetext{
${ }^{6}$ Matlab code that implements the second-order approximation technique proposed in Schmitt-Grohé and Uribe (2004c) is available on line at www.econ.duke.edu/ ${ }^{\sim}$ uribe.
} 


\subsection{Functional Forms}

We take from Christiano, Eichenbaum, and Evans (2003) the following functional forms for the period utility function, the production function, the investment adjustment cost function, and the map relating output loss to the level of capacity utilization:

$$
\begin{gathered}
U=\ln \left(c_{t}-b c_{t-1}\right)-\frac{\phi_{0}}{2} h_{t}^{2}+\phi_{1} \frac{m_{t}^{h^{1-\sigma_{m}}}}{1-\sigma_{m}} \\
F(k, h)=k^{\theta} h^{1-\theta} \\
\mathcal{S}\left(\frac{i_{t}}{i_{t-1}}\right)=\frac{\kappa}{2}\left(\frac{i_{t}}{i_{t-1}}-1\right)^{2}
\end{gathered}
$$

and

$$
a(u)=\gamma_{1}(u-1)+\frac{\gamma_{2}}{2}(u-1)^{2} .
$$

We note that because the function $a(u)$ is assumed to be quadratic, the second-order expansion of the right-hand side of the optimality condition (14)-i.e., the second-order expansion of $a^{\prime}\left(u_{t}\right)$ - is linear in $u$. Thus, potential second-order effects stemming from the curvature of $a^{\prime}(u)$ are left out. We also experimented with the alternative specification $a(u)=\frac{\gamma_{1}^{2}}{\gamma_{2}}\left[e^{\gamma_{2} / \gamma_{1}(u-1)}-1\right]$, which allows for curvature in $a^{\prime}(u)$. As in the case of the benchmark specification, however, we picked a two-parameter functional form because the calibration of Christiano et al. upon which we draw heavily, provides only independent information about the first and second derivatives of the capacity utilization cost function. Evaluated at the steady-state value of the degree of capacity utilization $(u=1)$, this function as well as its first and second derivatives take the same values as the benchmark quadratic specification. Moreover, this functional form has the property that all of its derivatives have a constant elasticity at the steady state equal to $\gamma_{2} / \gamma_{1}$. For the benchmark values assigned to $\gamma_{1}$ and $\gamma_{2}$, the welfare consequences of monetary policy reported below are identical under both specifications of the capacity utilization cost function.

\subsection{Calibration}

The time unit is meant to be one quarter. The calibration follows Christiano, Eichenbaum, and Evans (2003) and is summarized in table 1. We restrict the steady-state labor input, $h^{d}$, and the steady-state capacity utilization rate, $u$, to unity and steady-state profits to zero. The discount factor takes the value of 3 percent per annum. The share of capital in value added is assumed to be 36 percent. The depreciation rate of capital is set at 10 percent per year. The fraction of the wage bill that is subject to a working-capital constraint is 
Table 1: Calibration

\begin{tabular}{lcl}
\hline \hline Parameter & Value & Description \\
\hline$\beta$ & 0.9926 & Subjective discount factor \\
$\theta$ & 0.36 & Share of capital in value added \\
$\psi$ & 0.5827 & Fixed cost parameter \\
$\delta$ & 0.025 & Depreciation rate \\
$\nu$ & 1 & Fraction of wage bill subject to a CIA constraint \\
$\eta$ & 6 & Price-elasticity of demand for a specific good variety \\
$\tilde{\eta}$ & 21 & Wage-elasticity of demand for a specific labor variety \\
$1-\alpha$ & 0.4 & Fraction of firms setting prices optimally each quarter \\
$1-\tilde{\alpha}$ & 0.36 & Fraction of labor markets setting wages optimally each quarter \\
$b$ & 0.65 & Degree of habit persistence \\
$\phi_{0}$ & 1.1196 & Preference parameter \\
$\phi_{1}$ & 0.5393 & Preference parameter \\
$\sigma_{m}$ & 10.62 & Preference parameter \\
$\kappa$ & 2.48 & Parameter governing investment adjustment costs \\
$\chi$ & 1 & Degree of price indexation \\
$\tilde{\chi}$ & 1 & Degree of wage indexation \\
$\gamma_{1}$ & 0.0324 & Parameter governing capacity adjustment costs \\
$\gamma_{2}$ & 0.000324 & Parameter governing capacity adjustment costs \\
$\pi^{*}$ & 1.0103 & Gross inflation target \\
$z$ & 1 & Steady-state value of technology shock \\
$\lambda_{z}$ & 0.979 & Serial correlation of the log of the technology shock \\
$\eta_{z}$ & 0.0072 & Coefficient multiplying the innovation to the log of technology \\
$g$ & 0.5244 & Steady-state value of government spending \\
$\lambda_{g}$ & 0.96 & Serial correlation of the log of government spending \\
$\eta_{g}$ & 0.02 & Coefficient multiplying the innovation to the log of gov. spending \\
$\sigma$ & 0.18 & Parameter scaling the std. deviations of exogenous shocks \\
\hline \hline
\end{tabular}


assumed to be 100 percent. Households are assumed to hold 44 percent of the aggregate money supply in the steady state. The remaining 56 percent of money balances is held by firms. We set the long-run inflation rate to 4.2 percent per year which is consistent with the average growth rate of the U.S. GDP deflator over the period 1960-1998. We assume full indexation in prices and wages to the previous period's price inflation. That is, we set $\chi=\tilde{\chi}=1$. The degree of nominal rigidity is calibrated so that product prices change on average every 2.5 quarters and nominal wages every 2.8 quarters. Steady state markups are assumed to be 20 percent in product markets and 5 percent in labor markets. The degree of habit formation, defined by the parameter $b$, is set at 0.65 . The elasticity of the subutility function that depends on real balances is assigned a value of -9.62 , that is, $\sigma_{m}=10.62$. The steady-state elasticity of the marginal capacity utilization cost, $a^{\prime \prime}(1) / a^{\prime}(1)$, is calibrated to be 0.01 . The parameter $\kappa$ determining the degree of investment adjustment costs takes the value 2.48 .

Following Christiano and Eichenbaum (1992), the steady-state share of government purchases in value added is assumed to be 18 percent. The processes describing the evolution of the productivity shock and public spending are assumed to be univariate and first-order autoregressive in logs. Formally,

$$
\ln z_{t+1}=\lambda_{z} \ln z_{t}+\sigma \eta_{z} \epsilon_{t+1}^{z}
$$

and

$$
\ln \left(g_{t+1} / g\right)=\lambda_{g} \ln \left(g_{t} / g\right)+\sigma \eta_{g} \epsilon_{t+1}^{g} .
$$

The innovations $\epsilon_{t}^{z}$ and $\epsilon_{t}^{g}$ are assumed to be i.i.d. with mean zero and standard deviation equal to one. In the notation of equation (45), we have that $\Lambda=\left[\lambda_{g} 0 ; 0 \lambda_{z}\right]$ and $\tilde{\eta}_{\epsilon}=$ $\left[\eta_{g} 0 ; 0 \eta_{z}\right]$. King and Rebelo (1999) calibrate the productivity shock process by estimating an $\operatorname{AR}(1)$ representation for the Solow residual. We set $\lambda_{z}$ to 0.979 , which corresponds to their estimate of the first-order serial correlation of the Solow residual. As in Christiano and Eichenbaum (1992), we set $\lambda_{g}$ equal to 0.96. We calibrate the parameter $\eta_{z}$ to 0.0072 and the parameter $\eta_{g}$ to 0.02 . These values correspond to the volatility of the innovation to the Solow residual process estimated by King and Rebelo (1999) and to the volatility of the innovation to the government purchases process estimated by Christiano and Eichenbaum (1992), respectively.

To complete the calibration of the exogenous driving force process, it remains to pick a value for the parameter $\sigma$, which scales the volatility of the disturbances $\epsilon_{t}^{z}$ and $\epsilon_{t}^{g}$. Following the calibrations of King and Rebelo (1999) and Christiano and Eichenbaum (1992) would imply setting $\sigma$ to unity. However, for this value of the scaling parameter the Christiano- 
Eichenbaum-Evans model studied here implies an output volatility equal to 10 percent when monetary policy is assumed to take the form of a simple Taylor rule, $\hat{R}_{t}=1.5 \hat{\pi}_{t}$. Cooley and Prescott (1995) estimate that the volatility of the cyclical component of U.S. output in the postwar era is 1.72 percent, which is about six times smaller than the value implied by the model. One reason why the Christiano-Eichenbaum-Evans model implies such a high output volatility is that the assumed costs of varying the capital capacity utilization are modest, which allows firms to adjust the intensity at which they utilize the existing stock of capital fairly easily over the business cycle. We therefore set $\sigma$ to 0.18 , which brings the volatility of output down to 1.72 percent under a simple Taylor rule. We note however, that because the deviations of our welfare measure from steady state are proportional to $\sigma^{2}$, the welfare rankings of alternative monetary policies, which is at the core of the present study, is independent of the size of $\sigma^{2}$, provided the implied path for the nominal interest rate does not violate the zero lower bound.

\section{Dynamics Under a Taylor Rule}

To gather intuition about the dynamic behavior of the model economy, it is useful to analyze the equilibrium response of a number of macroeconomic variables of interest to supply and demand shocks. Before conducting such an exercise, it is necessary to specify a monetary regime. Here we assume that monetary policy takes the form of a simple interest-rate feedback rule whereby the short-term interest rate is set as an increasing function of deviations of inflation from a target, with a coefficient of 1.5. Formally, we assume that

$$
\hat{R}_{t}=1.5 \hat{\pi}_{t}
$$

According to the available empirical evidence (e.g., Taylor, 1993; and Clarida, Galí, and Gertler, 1998), this is a realistic policy benchmark for the U.S. economy and other industrialized countries over the past two decades. Arguably, a more realistic formulation of the interest-rate rule would feature the cyclical component of output and the lagged nominal interest rate as additional arguments of the interest-rate rule (Sack, 1998). However, such a rich feedback rule complicates the task of building intuition about the workings of the model. We will analyze richer rules later on when we perform policy evaluations.

Figure 1 displays the economy's response to a 1 percent increase in productivity $\left(z_{t}\right)$. In response to this shock, inflation and the nominal interest rate fall, while the average markup of prices over marginal cost increases. ${ }^{7}$ To understand why inflation falls in response to a

\footnotetext{
${ }^{7}$ We define the average markup in the economy as the sales-weighted average over markups charged by
} 
Figure 1: Response To A Unit Innovation In Technology Under A Simple Taylor Rule
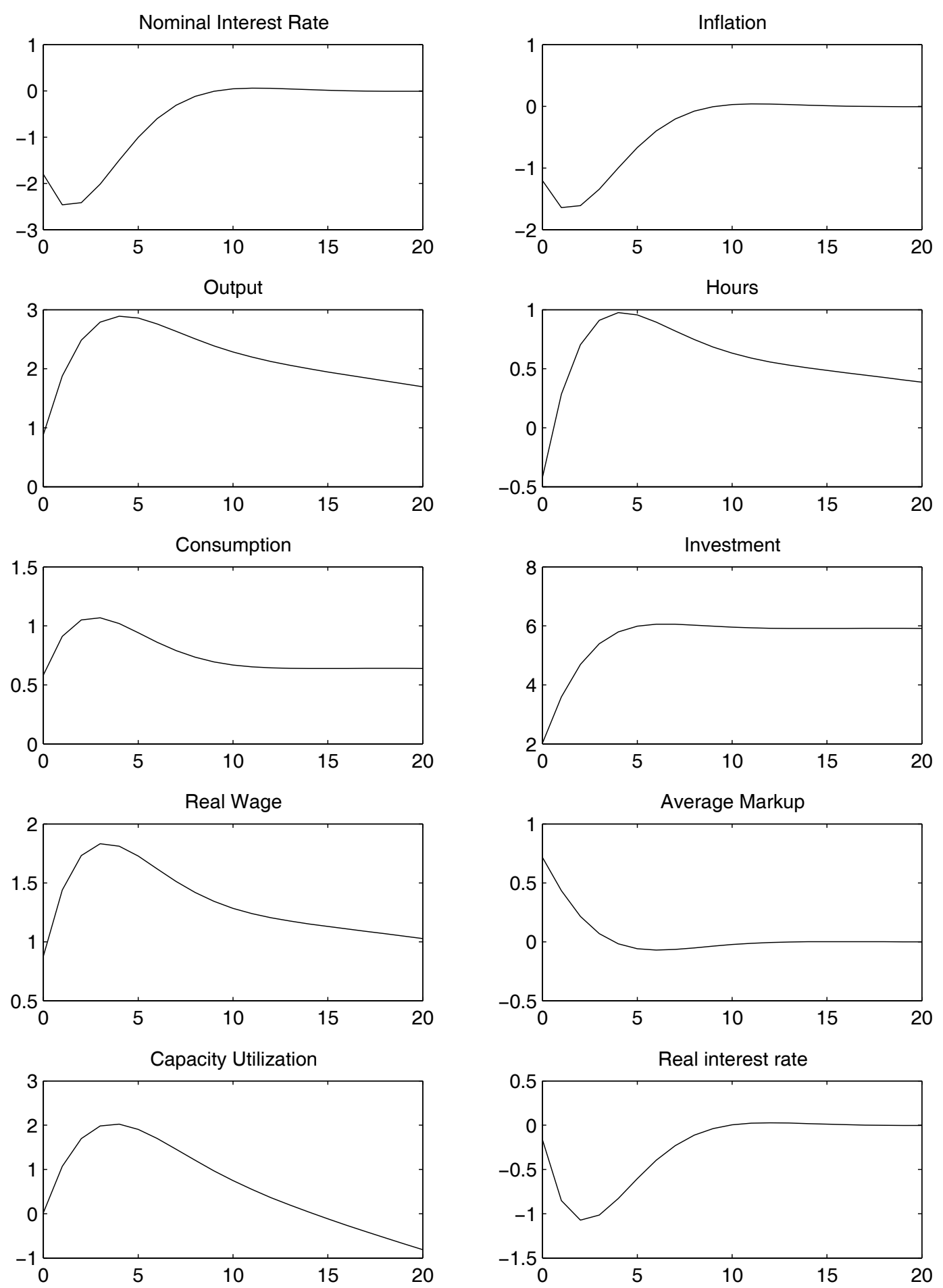
positive technology shock, it is crucial to analyze the behavior of the real interest rate. To see this, note that up to first order (and leaving aside uncertainty) the Taylor rule, $\hat{R}_{t}=1.5 \hat{\pi}_{t}$, together with the Fisher relation, $\hat{R}_{t}=\hat{\pi}_{t+1}+\hat{r}_{t}$, where $\hat{r}_{t}$ denotes the real interest rate, imply that inflation follows the first-order process $\hat{\pi}_{t+1}=1.5 \hat{\pi}_{t}-\hat{r}_{t}$. It is immediate from this difference equation that, because along the entire transition the real interest rate is below its steady-state level (bottom right panel of figure 1), in order for the inflation rate not to explode, it must be the case that inflation is below its steady-state level during the adjustment process.

The question, therefore, is why a positive productivity shock depresses real interest rates. The answer to this question has a lot to do with the magnitude of investment adjustment costs. In the absence of investment adjustment costs $(\kappa=0)$, the model studied here predicts that the real interest rate actually increases on impact and then falls gradually. This is because in the absence of investment adjustment costs, investment displays a large increase on impact, delaying the positive response of consumption. Indeed, in this case (habit-adjusted) consumption is hump-shaped. In order for consumers to be induced to undertake a hump-shaped habit-adjusted consumption profile, the real interest rate must be above its long-run level during the initial phase of the transition. By contrast, in the presence of investment adjustment costs ( $\kappa$ positive), which is the case under the baseline calibration of the model studied here, the real interest rate falls on impact. This decline occurs because in this case investment is slow to react to the productivity shock making consumption absorb much of the initial increase in output. As a result, habit-adjusted consumption increases on impact and then falls. To induce households to adopt such a declining spending path, the real interest rate must be below its steady-state value. It follows from this analysis, that when monetary policy takes the form of a simple Taylor Rule, an increase in productivity is inflationary in the absence of investment adjustment costs and is deflationary in their presence.

Having established why inflation falls in response to a positive productivity shock, one can also understand why markups are above average along the transition. Those firms that get to set prices optimally when the productivity shock occurs will tend to keep their markup close to its long-run mean. Note that equation (26) implies that in their price setting behavior these firms penalize more heavily deviations of markups from $\eta /(\eta-1)$ in the short run because demand is highest during this part of the transition. In addition, the fact that inflation falls on impact requires that firms that reoptimize prices in that period actually

individual firms. Formally, $\mu_{t}=\left[\int_{0}^{1} \mu_{i t} p_{i t} y_{i t} d i\right] /\left[\int_{0}^{1} p_{i t} y_{i t} d i\right]$. Recalling that $y_{i t}=p_{i t}^{-\eta} y_{t}$, that $\mu_{i t}=$ $p_{i t} / m c_{t}$, and that $s_{t}=\int_{0}^{1} p_{i t}^{-\eta} d i$, and defining $\bar{s}_{t}=\int_{0}^{1} p_{i t}^{2-\eta} d i$, we can write $\mu_{t}=\bar{s}_{t} /\left(s_{t} m c_{t}\right)$. Finally, note that $\bar{s}_{t}$ can be written recursively as $\bar{s}_{t}=(1-\alpha) \tilde{p}_{t}^{2-\eta}+\alpha \bar{s}_{t-1}\left(\pi_{t} / \pi_{t-1}^{\chi}\right)^{\eta-2}$, with $\bar{s}_{-1}$ given. 
lower nominal prices. This implies that the relative price of firms that get to change prices optimally, $\tilde{P}_{t} / P_{t}$, falls. Since markups for these firms are little changed, we deduce that real marginal costs fall. Now, since real marginal costs are common across all firms, the markup of firms who do not have the chance to reset prices optimally must go up. It follows that the average markup in the economy increases, as indicated by row 4 column 2 of figure 1. The increase in markups produces an inefficient macroeconomic adjustment in response to the productivity shock.

Recently, there has been a lively debate about the effect of technology shocks on hours worked. At the heart of the controversy is whether in post-Volker U.S. data hours increase or fall in response to a positive innovation in productivity. It is of interest to note that in the Christiano-Eichenbaum-Evans model hours fall on impact in response to a positive shock to labor productivity when monetary policy takes the form of a simple Taylor rule. If one believes that a simple interest-rate feedback rule whereby the short-term nominal interest rate depends only on consumer price inflation with a response coefficient of 1.5 is a reasonable description of U.S. monetary policy over the past two decades, then the ChristianoEichenbaum-Evans model is in line with those suggesting that the empirical evidence points to a decline in hours in response to a positive technology shock. It is fair to mention that in the empirical debate technology shocks are typically identified as permanent changes in total factor productivity, whereas in our study productivity shocks, although highly persistent, are assumed to follow a stationary autoregressive process.

One factor that contributes to the contractionary effect of productivity shocks on aggregate employment in the model is the presence of price stickiness in product markets. When the number of firms that do not get to reoptimize (reduce) prices after a positive technology shock is sufficiently large (i.e., when prices are sufficiently sticky), then the fact that employment at those firms falls drives the behavior of aggregate employment dominating the increase in employment at firms that get to reoptimize prices when the shock occurs.

Figure 2 displays the economy's response to a 1 percent increase in government spending. Because the increase in unproductive public spending makes households poorer, hours worked increase. To smooth out the necessary adjustment in consumption and leisure, the private sector reduces investment in physical capital and uses the existing capital stock more intensively. The resulting response of consumption is negative but negligible, reflecting the fact that households are fairly successful in smoothing out consumption expenditure. The flat time path of consumption implies a modest reaction in real interest rates. In turn, recalling that inflation is linked to real interest rates via the difference equation $\hat{\pi}_{t+1}=1.5 \hat{\pi}_{t}-\hat{r}_{t}$, the small response in real interest rates translates into an equally small response in inflation. The Taylor rule then implies that nominal interest rates are also little changed. 
Figure 2: Response To A Unit Innovation In Government Spending Under A Simple Taylor Rule
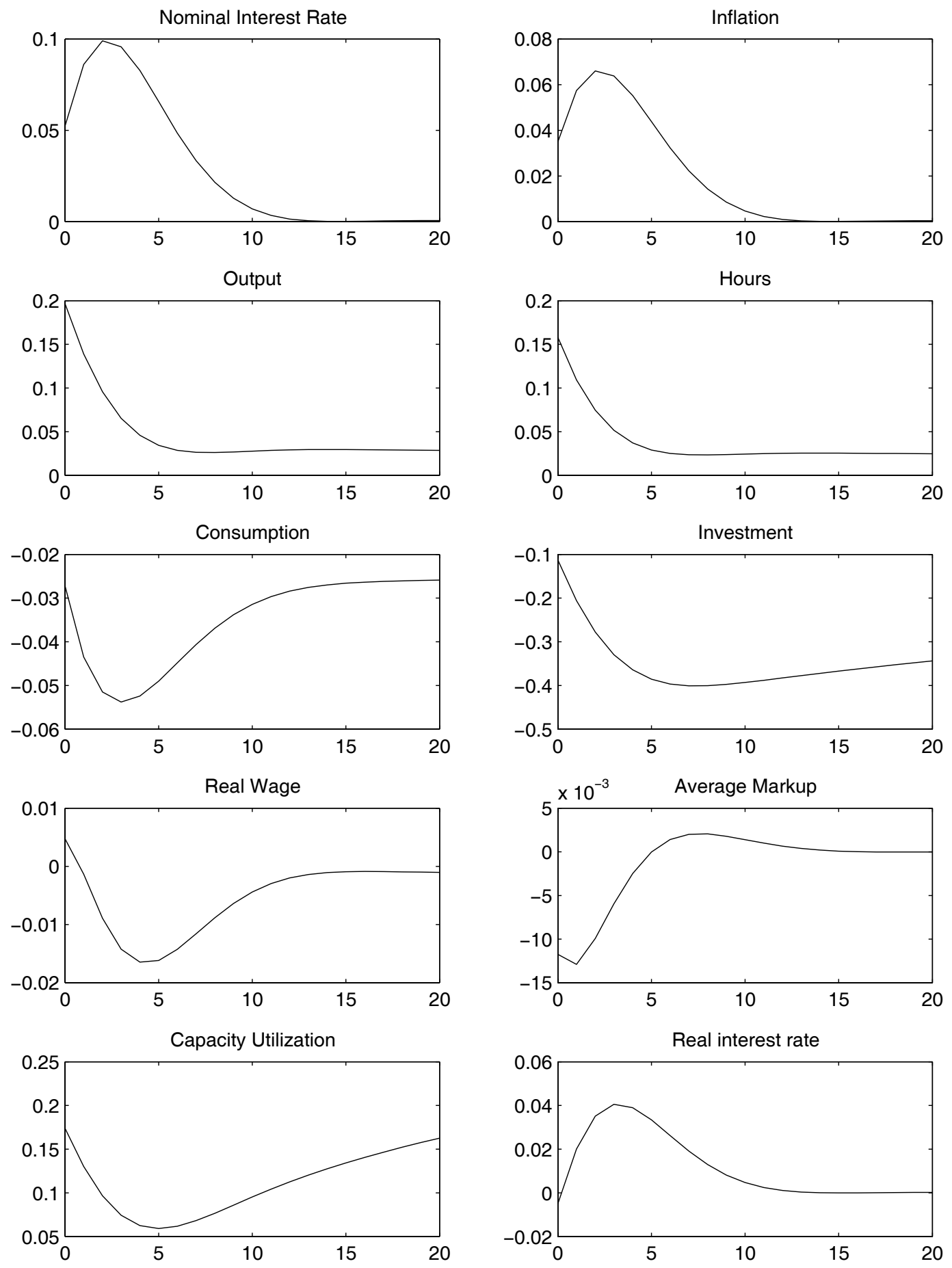


\section{The Welfare Measure}

We measure the level of utility associated with a particular monetary policy specification as follows. Let the equilibrium processes for consumption, money holdings, and hours associated with a particular monetary regime be denoted by $\left\{c_{t}, m_{t}^{h}, h_{t}\right\}$. Then we measure welfare as the conditional expectation of lifetime utility as of time zero evaluated at $\left\{c_{t}, m_{t}^{h}, h_{t}\right\}$. We denote this welfare measure by $V_{0}$. Formally, $V_{0}$ is given by

$$
V_{0} \equiv E_{0} \sum_{t=0}^{\infty} \beta^{t} U\left(c_{t}-b c_{t-1}, m_{t}^{h}, h_{t}\right)
$$

In addition, we assume that at time zero all state variables of the economy, including $c_{-1}$, equal their respective steady-state values. We depart from the usual practice of identifying the welfare measure with the unconditional expectation of lifetime utility because using unconditional expectations of welfare amounts to not taking into account the transitional dynamics leading to the stochastic steady state. Because the deterministic steady state is the same across all policy regimes we consider, our choice of computing expected welfare conditional on the initial state being the nonstochastic steady state ensures that the economy begins from the same initial point under all possible policies. Therefore, our strategy will deliver the constrained optimal monetary rule associated with a particular initial state of the economy. It is of interest to investigate the robustness of our results with respect to alternative initial conditions. For, in principle, the welfare ranking of the alternative polices will depend upon the assumed value for (or distribution of) the initial state vector. For further discussion of this issue, see Kim et al., 2003.

We compute the welfare cost of a particular monetary regime relative to a reference rule as follows. Consider two policy regimes, a reference policy regime denoted by $r$ and an alternative policy regime denoted by $a$. Then we define the welfare associated with policy regime $r$ as

$$
V_{0}^{r}=E_{0} \sum_{t=0}^{\infty} \beta^{t} U\left(c_{t}^{r}-b c_{t-1}^{r}, m_{t}^{h r}, h_{t}^{r}\right),
$$

where $c_{t}^{r}, m_{t}^{h r}$, and $h_{t}^{r}$ denote the contingent plans for consumption, real money balances, and hours under policy regime $r$. Similarly, define the welfare associated with policy regime $a$ as

$$
V_{0}^{a}=E_{0} \sum_{t=0}^{\infty} \beta^{t} U\left(c_{t}^{a}-b c_{t-1}^{a}, m_{t}^{h a}, h_{t}^{a}\right) .
$$

Let $\lambda$ denote the welfare cost of adopting policy regime $a$ instead of the reference policy regime $r$. We measure $\lambda$ as the fraction of regime $r$ 's consumption process that a household 
would be willing to give up to be as well off under regime $a$ as under regime $r$. That is, $\lambda$ is implicitly defined by

$$
V_{0}^{a}=U\left(c_{0}^{r}(1-\lambda)-b c_{-1}, m_{0}^{h r}, h_{0}^{r}\right)+E_{0} \sum_{t=1}^{\infty} \beta^{t} U\left(\left(c_{t}^{r}-b c_{t-1}^{r}\right)(1-\lambda), m_{t}^{h r}, h_{t}^{r}\right)
$$

Note that we do not apply the factor $1-\lambda$ to $c_{-1}$, because this variable is predetermined at the time of the policy evaluation. Using the particular functional form assumed for the period utility function, equation (49) can be written as

$$
V_{0}^{a}-V_{0}^{r}=\ln \left[(1-\lambda) c_{0}^{r}-b c_{-1}\right]+\frac{\beta}{1-\beta} \ln (1-\lambda)-\ln \left(c_{0}^{r}-b c_{-1}\right)
$$

Resorting to the notation introduced in section 3, let $V_{0}^{a}=g^{v a}\left(x_{0}, \sigma\right), V_{0}^{r}=g^{v r}\left(x_{0}, \sigma\right)$, and $\ln c_{0}=g^{c r}\left(x_{0}, \sigma\right)$, where $x_{0}$ is the value of the state vector in period zero and $\sigma$ is a parameter scaling the standard deviation of the exogenous shocks. Then we can rewrite the above expression as

$$
g^{v a}\left(x_{0}, \sigma\right)-g^{v r}\left(x_{0}, \sigma\right)=\ln \left[(1-\lambda) e^{g^{c r}\left(x_{0}, \sigma\right)}-b c_{-1}\right]+\frac{\beta}{1-\beta} \ln (1-\lambda)-\ln \left(e^{g^{c r}\left(x_{0}, \sigma\right)}-b c_{-1}\right) .
$$

It is clear from this expression that $\lambda$ is a function of $x_{0}$ and $\sigma$, which we write as

$$
\lambda=\Lambda\left(x_{0}, \sigma\right)
$$

Consider a second-order approximation of the function $\Lambda$ around the point $x_{0}=x$ and $\sigma=0$, where $x$ denotes the deterministic steady-state of the state vector. Because we wish to characterize welfare conditional upon the initial state being the deterministic steady state, that is, $x_{0}=x$, in performing the second-order expansion of $\lambda$ only its first and second derivatives with respect to $\sigma$ have to be considered. Formally, we have

$$
\lambda \approx \Lambda(x, 0)+\Lambda_{\sigma}(x, 0) \sigma+\frac{\Lambda_{\sigma \sigma}(x, 0)}{2} \sigma^{2}
$$

Because the deterministic steady-state level of welfare is the same across all monetary policies belonging to the class defined in equation (33), it follows that $\lambda$ vanishes at the point $x_{0}=x$ and $\sigma=0$. Formally,

$$
\Lambda(x, 0)=0
$$

Totally differentiating equation (48) with respect to $\sigma$ and evaluating the result at $\left(x_{0}, \sigma\right)=$ 
$(x, 0)$ one obtains

$$
g_{\sigma}^{v a}(x, 0)-g_{\sigma}^{v r}(x, 0)=\frac{1}{1-b}\left[g_{\sigma}^{c r}(x, 0)-\Lambda_{\sigma}(x, 0)\right]+\frac{\beta}{1-\beta} \Lambda_{\sigma}(x, 0)-\frac{1}{1-b} g_{\sigma}^{c r}(x, 0)
$$

Schmitt-Grohé and Uribe (2004c) show that the first derivatives of the policy functions with respect to $\sigma$ evaluated at $x_{t}=x$ and $\sigma=0$ are nil (so $g_{\sigma}^{v a}=g_{\sigma}^{v r}=g_{\sigma}^{c r}=0$ ). It follows immediately from the above expression that

$$
\Lambda_{\sigma}(x, 0)=0
$$

Now totally differentiating (48) twice with respect to $\sigma$ and evaluating the result at $\left(x_{0}, \sigma\right)=$ $(x, 0)$ yields

$$
\Lambda_{\sigma \sigma}(x, 0)=-\frac{g_{\sigma \sigma}^{v a}(x, 0)-g_{\sigma \sigma}^{v r}(x, 0)}{\frac{\beta}{1-\beta}+\frac{1}{1-b}} .
$$

Thus, our welfare cost measure, in percentage terms, is given by

$$
\text { welfare cost }=-\frac{g_{\sigma \sigma}^{v a}(x, 0)-g_{\sigma \sigma}^{v r}(x, 0)}{\frac{\beta}{1-\beta}+\frac{1}{1-b}} \times \frac{\sigma^{2}}{2} \times 100
$$

As mentioned above, in deriving this measure of welfare costs we do not apply the factor $1-\lambda$ to the level of consumption in period -1 . Alternatively, one could define the welfare cost index applying the factor $1-\lambda$ to the entire argument of the first term of the initial period's utility function, $c_{0}-b c_{-1}$, rather than just to $c_{0}$. In this case, $\lambda$ is implicitly given by $V_{0}^{a}=E_{0} \sum_{t=0}^{\infty} \beta^{t} U\left(\left(c_{t}^{r}-b c_{t-1}^{r}\right)(1-\lambda), m_{t}^{h r}, h_{t}^{r}\right)$. A second-order-accurate measure of welfare costs is then given by $-(1-\beta)\left[g_{\sigma \sigma}^{v a}(x, 0)-g_{\sigma \sigma}^{v r}(x, 0)\right] \times\left(\sigma^{2} / 2\right) \times 100$. Clearly, because this welfare measures is proportional to the one we adopt, both measure will deliver identical welfare rankings. Moreover, under the baseline calibration adopted in this paper the ratio of the welfare cost measure we adopt to the alternative discussed here is 0.9865 . Therefore, both criteria deliver almost identical welfare cost numbers. ${ }^{8}$

\footnotetext{
${ }^{8}$ The reason why $\lambda$ is always bigger in absolute value under the alternative welfare cost measure is quite intuitive. Suppose that the reference policy $(r)$ yields less welfare than the alternative policy $(a)$. In this case, $\lambda$ is negative, because households living under the reference policy must be compensated by an increase in consumption. However, if the increase in consumption also applies to the initial stock of habit $c_{-1}$, as is the case under the welfare cost criterion not adopted in this paper, then the compensated initial stock of habit is higher making the agent worse off. As a result $\lambda$ must be bigger.
} 


\section{Policy Evaluation}

In our search for the optimal monetary rule, we limit attention to what we call operational rules. To be operational, an interest-rate rule must set the nominal interest rate as a function of a few readily observable macroeconomic variables. We study rules where the nominal interest rate responds to its own lag, inflation, and output. In addition, an operational rule is required to posses the following two properties: First, it must induce a locally unique rational expectations equilibrium. ${ }^{9}$ Second, operational rules must satisfy the nonnegativity constraint on the nominal interest rate. For technical reasons, we are unable to impose this constraint directly. Specifically, the second-order perturbation approach we apply in our numerical work is ill equipped to handle occasionally binding constraints. ${ }^{10}$ Instead, we require that under an operational rule the target value for the nominal interest rate be greater than two times the standard deviation of the nominal interest rate. Formally, we require that $\ln \left(R^{*}\right) \geq 2 \sigma_{\hat{R}_{t}}$. If the equilibrium nominal interest rate was normally distributed around its target value, then this constraint would ensure a positive nominal interest rate 98 percent of the time. A possible alternative would be to require that the unconditional mean of the nominal interest rate, rather than its target value, be greater than 2 standard deviations of the nominal interest rate, that is, $E \ln R_{t}>2 \sigma_{\hat{R}_{t}}$. One reason why we do not pursue this alternative is that it is computationally more costly. This is because obtaining a second-order accurate approximation to the unconditional mean of the nominal interest rate requires approximating the equilibrium up to second order, whereas obtaining a second-order accurate approximation to the variance of the nominal interest rate requires approximating the equilibrium conditions only up to first order. Admittedly, as long as $E \ln R_{t}<\ln R^{*}$, the criterion $\ln R^{*}>2 \sigma_{\hat{R}_{t}}$ is less restrictive than the criterion $E \ln R_{t}>2 \sigma_{\hat{R}_{t}}$. Indeed, in our economy, there is a tendency for optimal policy to induce a mean interest rate below the target $R^{*}$. This is because the demand for money in combination with indexation creates incentives for policy to gravitate toward the Friedman rule. As we show later, however, although the operational rule that we identify as optimal implies that $E \ln R_{t}<\ln R^{*}$, it satisfies the tighter criterion $E \ln R_{t}>2 \sigma_{\hat{R}_{t}}$.

An operational rule is judged to be optimal when it yields a higher level of welfare to the representative agent than any other operational rule.

\footnotetext{
${ }^{9} \mathrm{An}$ alternative, not pursued in this study, is to enlarge the set of operational monetary rules by allowing for policy regimes that render the equilibrium locally indeterminate. This approach requires introducing plausible assumptions about the expectations coordination mechanism, which is outside the scope of our investigation.

${ }^{10}$ Other authors have also faced the need to circumvent the problem of not being able to directly impose the zero-bound constraint on nominal interest rates. See, for instance, Rotemberg and Woodford (1999, p. $75)$.
} 
The family of interest-rate rules presented in equation (33) can be fully characterized by four parameters, namely, $\alpha_{\pi}$, measuring the responsiveness of interest rates to deviations of inflation from the central bank's target, $\alpha_{y}$, the output-gap coefficient, $\alpha_{R}$, measuring the degree of policy inertia, and $i$, measuring the backward-, current-, or forward-looking nature of policy. We further restrict the policy quadruple $\left(\alpha_{\pi}, \alpha_{y}, \alpha_{R}, i\right)$ to lie in the following space: The parameters $\alpha_{\pi}$, measuring the responsiveness of interest rates to deviations of inflation from the central bank's target, and $\alpha_{y}$, the output gap coefficient, are confined to take values in the interval -3 and 3 . For both $\alpha_{\pi}$ and $\alpha_{y}$, we consider a grid with a step size of 0.0625 . The degree of policy inertia, measured by the parameter $\alpha_{R}$, can take 3 possible values, 0,1 , and 2. When $\alpha_{R}$ equals zero we say that policy lacks inertia. When $\alpha_{R}$ equals unity, policy is referred to as inertial. And, following the terminology of Rotemberg and Woodford (1999), when $\alpha_{R}$ equals two, we say that policy is superinertial. Finally, we consider three possible values for the parameter $i, 1,0$, and -1 . When $i=1$, the central bank is backward-looking in the sense that it sets interest rates based on past information regarding inflation and output. When $i$ equals zero, the central bank responds to contemporaneous realizations of inflation and the output gap. And when $i=-1$, the monetary authority is forward-looking, as the current instrument setting is a function of expectations of future price and output movements. Summarizing, our discretized policy parameter space contains 97 possible values for $\alpha_{\pi}, 97$ possible values for $\alpha_{y}, 3$ possible values for $\alpha_{R}$, and 3 possible values for $i$. This implies that we evaluate a total of 84,681 different monetary policy regimes.

An alternative to our approach of discretizing the policy space would be to rely on a numerical optimization routine to find the optimal interest-rate rule coefficients $\alpha_{\pi}, \alpha_{y}$, and $\alpha_{R}$ for each value of the policy parameter $i$. The reason why we choose not to adopt this numerical strategy is that it identifies local extrema. And, as will become clear shortly, in our model economy, welfare is a nonmonotonic function of the policy parameters, with several local maxima.

\subsection{Welfare Surfaces}

Figure 3 shows the level of welfare associated with the different policy rules as functions of the policy parameters $\alpha_{\pi}$ and $\alpha_{y}$ holding constant the degree of policy inertia $\alpha_{R}$ and the parameter $i$ indicating whether the rule is backward-, current-, or forward-looking. The welfare measure that is plotted corresponds to a second-order approximation to the expression given in equation (46). Only policies that imply a welfare cost of at most 0.1 percent of the lifetime consumption stream under the best operational rule are shown. The welfare surfaces appear to be piecewise smooth in $\alpha_{\pi}$ and $\alpha_{y}$. However, the welfare graph displays 
Figure 3: Welfare as a Function of $\alpha_{\pi}$ and $\alpha_{y}$
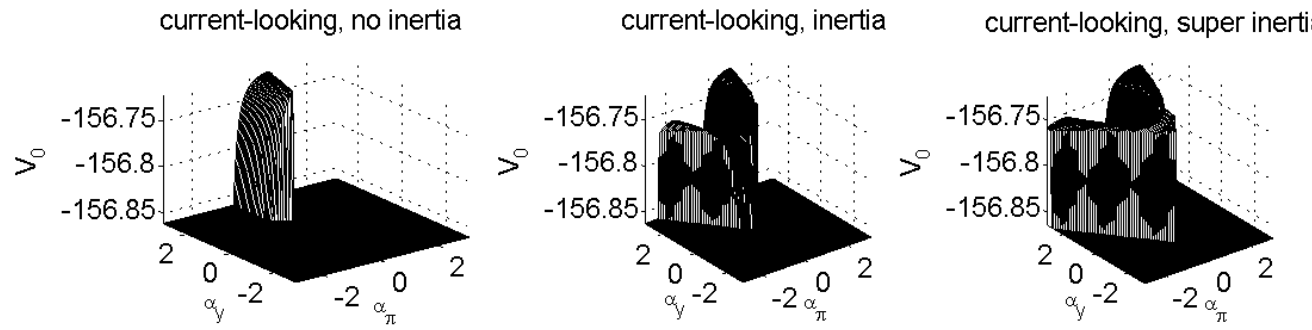

backward-looking, no inertia

backward-looking, inertia

backward-looking, super inertia
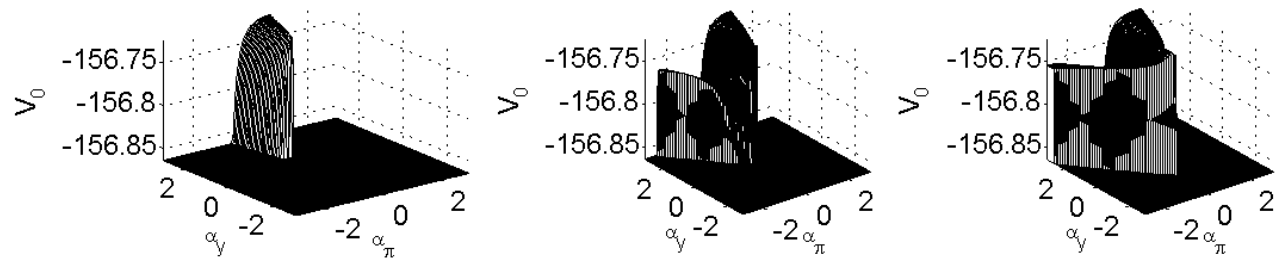

forward-looking, no inertia

forward-looking, inertia

forward-looking, super inertia
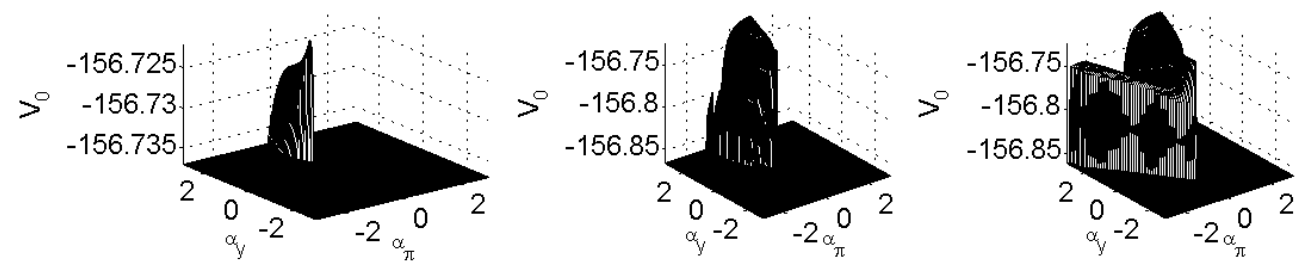
multiple local maxima. This feature motivates our choice of finding the optimal interest rate rule using a grid search over the policy parameters rather than relying on local optimization routines.

Figure 4 depicts in black the pairs $\alpha_{\pi}$ and $\alpha_{y}$ for which the associated equilibrium is determinate but the zero-bound constraint is violated, with grey the pair for which the equilibrium is determinate and the zero-bound constraint is satisfied, and with white the pairs for which the equilibrium fails to be locally determinate, given values for the policy parameters $\alpha_{R}$ and $i$. A cross marks the optimal operational rule given $\alpha_{R}$ and $i$. Each row of graphs reveals a tight connection between the degree of interest-rate smoothing, $\alpha_{R}$, and the threshold value for the inflation sensitivity parameter $\alpha_{\pi}$ above which an operational rule exists. In the absence of inertia $\left(\alpha_{R}=0\right.$, left column), operational rules exist only for inflation coefficients greater than unity $\left(\alpha_{\pi}>1\right)$. This stability condition also appears in simpler monetary models. When policy is inertial $\left(\alpha_{R}=1\right.$, middle column), operational rules exist for values of $\alpha_{\pi}$ greater than zero, and when policy is superinertial $\left(\alpha_{R}=2\right.$, right column), operational rules exist for $\alpha_{\pi}>-1$. This relation suggests a pattern according to which operational rules exist only for values of $\alpha_{\pi}$ greater than $1-\alpha_{R}$. The area of operational rules is roughly symmetric around acyclical rules $\left(\alpha_{y}=0\right)$. As a result, the more cyclical is the rule (whether pro- or countercyclical) the less likely it is to be operational. For the subclass of acyclical rules, the set of operational rules is the same as the set of rules that induce a locally determinate equilibrium.

\subsection{The Optimal Operational Rule}

Table 2 displays the inflation and output coefficients of the operational rules that maximize welfare for each of the 3 values of the degree of policy inertia considered $\left(\alpha_{R}=0,1,2\right)$ and for each of the 3 values taken by the parameter $i$ measuring the current-, backward-, or forward-looking nature of policy. The table also shows the level of welfare attained by each optimized rule and the associated welfare cost relative to the best operational rule using the welfare cost measure given in equation (49).

The optimal operational rule takes the form

$$
\hat{R}_{t}=1.125 E_{t} \hat{\pi}_{t+1}-0.0625 E_{t} \hat{y}_{t+1}
$$

This rule can be interpreted as a real-interest-rate targeting rule, for it is forward looking, has an inflation coefficient close to unity, has an output coefficient of about zero, and displays no inertia. Importantly, the inflation coefficient, although close to unity, is in accordance with the Taylor principle, prescribing a more than one-to-one response of interest rates to 
Figure 4: Determinacy of Equilibrium and Operational Rules
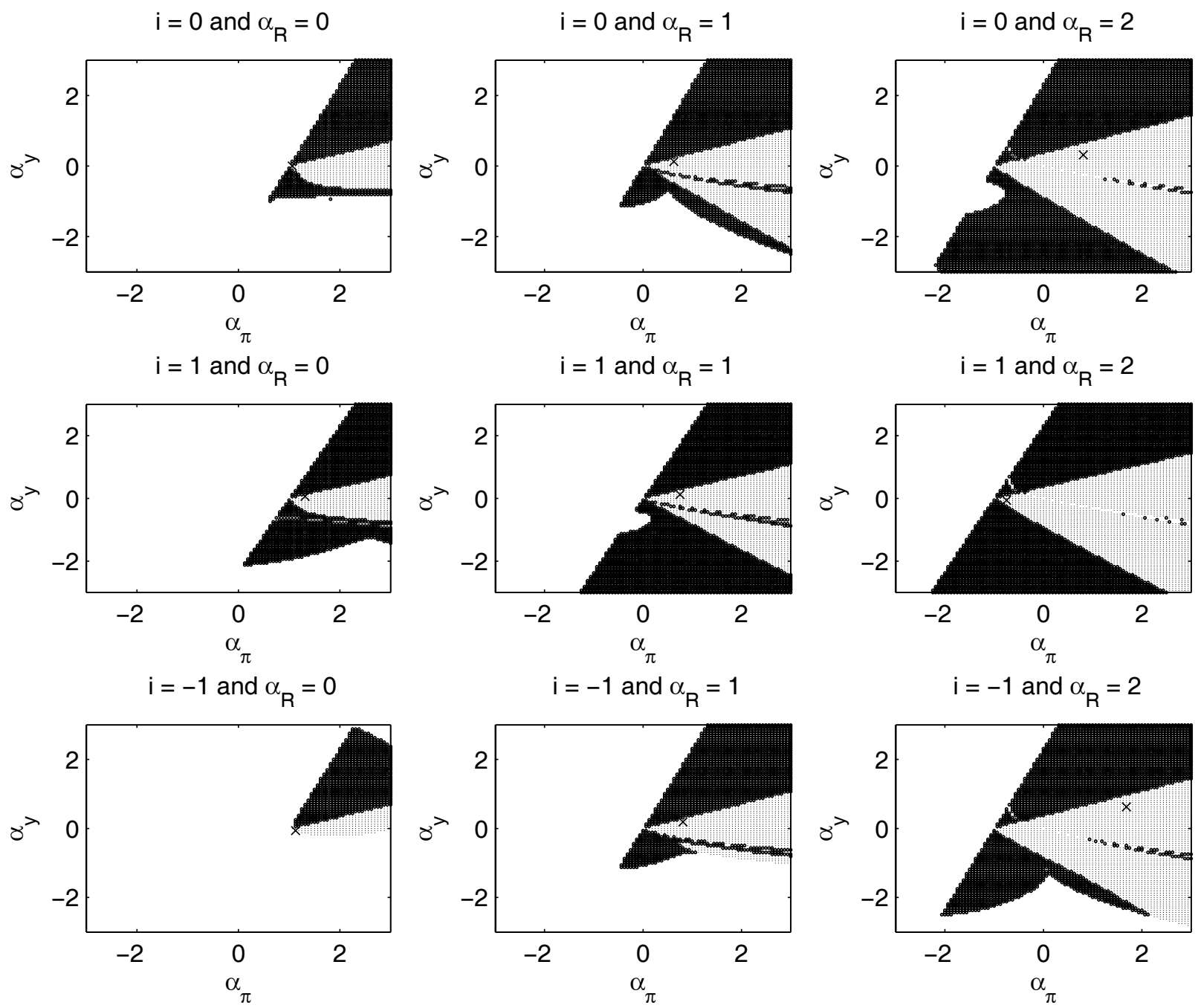

Note: White region: Equilibrium is not locally determinate. Black region: Equilibrium is locally determinate but zero-bound constraint is violated. Gray region: Equilibrium is locally determinate and zero-bound condition is satisfied. Cross: Optimal operational rule for given $\alpha_{R}$ and $i$. 
Table 2: Optimal Operational Interest-Rate Rules

\begin{tabular}{lcccc}
\hline \hline \multicolumn{4}{c}{ Optimized Interest-Rate Rules $\hat{R}_{t}=\alpha_{\pi} E_{t} \hat{\pi}_{t-i}+\alpha_{y} E_{t} \hat{y}_{t-i}+\alpha_{R} \hat{R}_{t-1}$} \\
\hline Current-Looking Rules $(i=0)$ & $\alpha_{\pi}$ & $\alpha_{y}$ & Welfare & Welfare Cost \\
No Inertia $\left(\alpha_{R}=0\right)$ & 1.0625 & 0 & -156.7227 & 0.0005 \\
Inertia $\left(\alpha_{R}=1\right)$ & 0.625 & 0.1250 & -156.7237 & 0.0012 \\
Super Inertia $\left(\alpha_{R}=2\right)$ & 0.8125 & 0.3125 & -156.7248 & 0.0020 \\
\hline Backward-Looking Rules $(i=1)$ & & & & \\
No Inertia $\left(\alpha_{R}=0\right)$ & 1.3125 & 0.0625 & -156.7233 & 0.0009 \\
Inertia $\left(\alpha_{R}=1\right)$ & 0.75 & 0.1250 & -156.7243 & 0.0017 \\
Super Inertia $\left(\alpha_{R}=2\right)$ & -0.75 & -0.0625 & -156.7250 & 0.0022 \\
\hline Forward-Looking Rules $(i=-1)$ & & & & \\
No Inertia $\left(\alpha_{R}=0\right)$ & 1.1250 & -0.0625 & -156.7220 & 0 \\
Inertia $\left(\alpha_{R}=1\right)$ & 0.8125 & 0.1875 & -156.7232 & 0.0008 \\
Super Inertia $\left(\alpha_{R}=2\right)$ & 1.6875 & 0.6250 & -156.7237 & 0.0012 \\
\hline Non-Optimized Rules & \multicolumn{4}{c}{ Indeterminate } \\
Inflation Targeting $\left(\hat{\pi}_{t}=0\right)$ & - & - & Zero-bound violated \\
Taylor Rule & 1.5 & 0.5 & -156.7261 & 0.0029 \\
Simple Taylor Rule & 1.5 & - &
\end{tabular}

Note: (1) $R_{t}$ denotes the gross nominal interest rate, $\pi_{t} \equiv P_{t} / P_{t-1}$ denotes the gross inflation rate, and $y_{t}$ denotes output. (2) For any variable $x_{t}$, its nonstochastic steady-state value is denoted by $x$, and its log-deviation from steady state by $\hat{x}_{t} \equiv \ln \left(x_{t} / x\right)$. (3) In all cases, the parameter $\alpha_{\pi}$ is restricted to lie in the interval $[-3,3]$ while $\alpha_{y}$ is restricted to be in the interval $[-3,3]$. (4) Welfare is computed as a second-order approximation to the expression in equation (46), conditional on that period's state being the non-stochastic steady state. (5) The welfare cost is measured relative to the optimal rule $\left(\alpha_{\pi}=1.125, \alpha_{y}=-0.0625\right.$, $\alpha_{R}=0$, and $i=-1$ ), and is defined in equation (49). 
deviations of inflation from target.

Real-interest-rate targeting appears to be a robust feature of optimal operational policy. In effect, even if one limits attention to either contemporaneous- or backward-looking rules, the optimal rule lacks inertia, is acyclical in the sense that the output coefficient is nil, and features an inflation coefficient close to 1 . The finding that real-interest-rate targeting is optimal even when policy is restricted to being contemporaneous or backward looking is important because some may argue that a forward-looking rule is not truly operational. For forward-looking rules require knowledge on the part of the central bank of the private sector's expectations of future output and inflation, which is not readily observable information. Moreover, some may argue that in practice current realizations of output and inflation are not in the information set of the monetary authority at the time it makes policy decisions, thus disqualifying current-looking rules from the set of operational rules. For these critics, a rule is operational only when it is based on past observations of macroeconomic indicators. Table 2 shows that the welfare costs of restricting policy to be operational in this tighter sense are negligible. Specifically, the welfare cost of the best backward-looking rule vis-à-vis the optimal rule is only 0.0009 percent of consumption per period.

Table 2 also reports welfare evaluations of some commonly prescribed non-optimized monetary policy rules. A monetary rule whereby the inflation rate is at its target in and out of equilibrium, labeled inflation targeting in the bottom panel of table 2, induces indeterminacy of the rational expectations equilibrium. For this reason, we are unable to evaluate the welfare consequences of such a policy. A standard Taylor rule with an inflation coefficient of 1.5 and an output coefficient of 0.5 fails to be operational, as it implies that $2 \sigma_{\hat{R}_{t}}>\ln R^{*}$ so that the associated equilibrium frequently violates the zero bound on nominal interest rates. A simpler Taylor rule, with an inflation coefficient of 1.5 and an output coefficient of 0 does satisfy all of the requirements of an operational rule. It entails a welfare cost of 0.0029 percent of the lifetime consumption associated with the optimal rule. This welfare cost number, although small in absolute terms, is greater than those associated with any of the optimized rules shown in table 2.

\subsection{Inertia, Cyclicality, and the Taylor Principle}

The three main characteristics of the optimal operational rule are lack of inertia in interest rates $\left(\alpha_{R}=0\right)$, acyclicality ( $\alpha_{y}$ close to zero), and a mildly active response to inflation (i.e., an inflation coefficient greater than and close to unity). These three features of optimal policy survive a large number of fundamental modifications to the baseline model.

Table 4 presents the optimal operational rule for 7 variations of the baseline model: (1) 
indexation to long-run inflation (i.e., non-reoptimized prices/wages are adjusted by the factor $\pi^{*}$ each period); (2) flexible wages $(\tilde{\alpha}=0.01)$; (3) flexible prices $(\alpha=0.01)$; (4) Higher costs of varying capacity utilization $\left(\gamma_{2} / \gamma_{1}=2\right)$; (5) No habit formation $(b=0)$; (6) No money held by households $\left(\phi_{1}=0\right)$; and (7) no money at all $\left(\phi_{1}=\nu=0\right)$.

Under all model variations considered, optimal operational policy lacks inertia in interest rates. An exception is the case in which prices are indexed to long-run inflation. Interestingly, indexation to long-run inflation is implicitly or explicitly assumed in related studies that identify inertia as a feature of optimal monetary policy (e.g., Rotemberg and Woodford, 1999). This result underlines the importance of the exact indexation modality in shaping optimal policy.

The Taylor principle prescribing interest rate rules with an inflation coefficient greater than one is present in 5 of the 7 perturbations to the baseline model we perform. The largest inflation coefficient obtains under flexible wages, where $\alpha_{\pi}=3$. This number indeed hits the upper bound imposed in our numerical computations. Intuitively, when wages are flexible, the monetary authority has a larger incentive to stabilize inflation to ameliorate the consequences of the sticky-price distortion. In this case, the central bank stabilizes inflation by setting the inflation coefficient in the interest-rate rule as high as it can. As a result, the equilibrium under flexible wages features a standard deviation of inflation of only 0.5 percent, 4 times smaller than in the baseline model.

Another robust feature of optimal operational rules appears to be a muted response of interest rates to output. This result cannot be immediately related to the findings in the related literature. The reason is that in most existing studies the central bank is assumed to respond to a sophisticated output gap measure given by the difference between actual output and the level of output that would obtain in a world without nominal rigidities. As we mentioned earlier, this measure of the output gap is not readily observable and thus does not satisfy our requirement of operationality.

\subsection{Optimal Macroeconomic Adjustment}

Figure 5 compares the dynamic response of the model economy induced by a 1-percent technology shock under the optimal operational rule (solid line) to that arising under a simple Taylor rule (broken line). The response of the real side of the economy is remarkably similar under both rules. Under the optimal rule, however, the productivity shock produces smaller though more persistent fluctuations in all real variables. In particular, the real interest rate displays a much smoother response under the optimal rule than under the simple Taylor rule. On the nominal side, both rules call for an immediate easing in monetary policy to 
Figure 5: Comparing the Optimal Rule with a Simple Taylor Rule: Response to a Unit Innovation in Technology
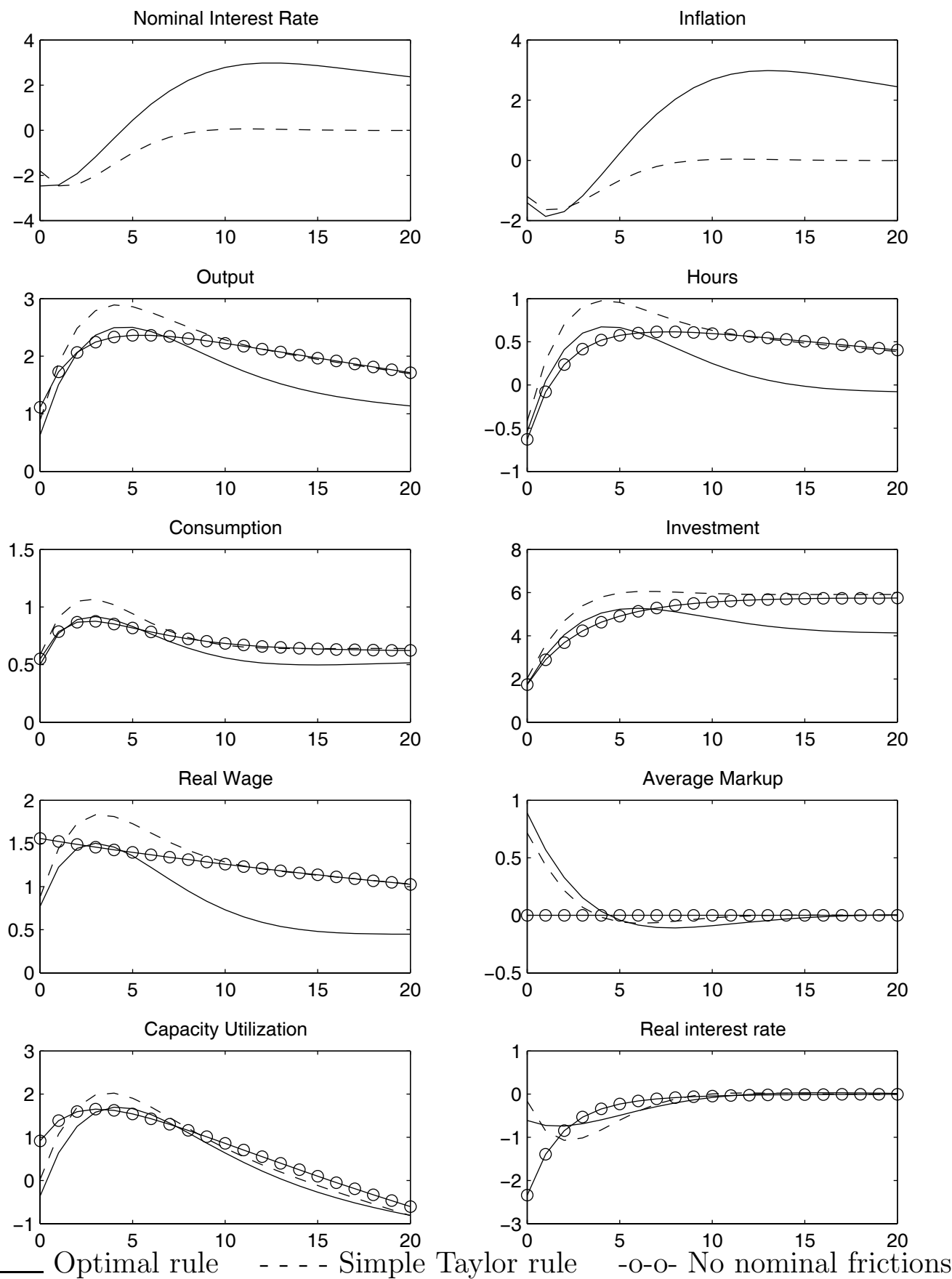

Notes: (1) The optimal rule takes the form $\hat{R}_{t}=1.125 E_{t} \hat{\pi}_{t+1}-0.0625 E_{t} \hat{y}_{t+1}$. The simple Taylor rule takes the form $\hat{R}_{t}=1.5 \hat{\pi}_{t}$. The economy without nominal frictions features $\nu=\phi_{1}=\alpha=\tilde{\alpha}=0$. (2) The impulse is a 1 percent increase in the productivity shock $z_{t}$. All real variables except for the real interest rate are expressed in percent deviations from their respective steady-state values. The real interest rate, the nominal interest rate, and inflation are expressed in annual percent-point deviations from steady state. 
accommodate the expansion caused by the improvement in productivity. However, under the optimal rule the initial reduction in nominal interest rates is accompanied by a commitment to tighten money market conditions in the future. By contrast, under the simple Taylor rule the nominal interest rule remains below target along the entire transition. As a consequence, the two rules induce quite different inflationary dynamics. Under the best operational rule an initial decline in inflation is accompanied by a large future increase in prices, whereas under the simple Taylor rule this overshooting of inflation is absent.

As a point of reference, figure 5 also shows, with a circled line, the dynamics of an economy without any of the 4 nominal frictions that impede efficient adjustment in the baseline model. That is, an economy with flexible prices and wages $(\alpha=\tilde{\alpha}=0)$, and without a demand for money by households or firms $\left(\phi_{1}=\nu=0\right) .{ }^{11}$ The optimal operational rule does a remarkably good job at replicating the dynamics of the efficient economy during the initial phase of the transition. On the other hand, for the later part of the transition the Taylor rule keeps the real allocation closer to that associated with the economy without nominal frictions. Our welfare evaluation suggests that the welfare gains of mimicking the initial transition outweigh the benefits of replicating the later part of the adjustment. Recall, however, that the welfare differences between the best operational rule and the simple Taylor rule are minimal.

\subsection{Is Inflation Stabilization Desirable?}

Much of the existing literature on optimal monetary policy in the neo-Keynesian tradition has stressed the importance of inflation stabilization as a central goal of monetary policy. A general result that emerges from this body of work is that as Woodford (2004) puts it in his recent survey of the inflation targeting literature, "it is not a bad first approximation to say that the goal of monetary policy should be price stability." This conclusion emerges from models that are highly stylized in the sense that they include a small number of nominal and real frictions.

Price stability ceases to dominate the monetary policy prescription in the richer theoretical environment studied in this paper. Specifically, table 3 shows that under the optimal operational rule price inflation is significantly volatile, with a standard deviation of 2 percent per annum, about half the U.S. mean inflation in the past 4 decades. The main force driving the optimality of relatively high inflation volatility is the assumed indexation of wages and prices to the lagged rate of inflation. As shown on line 2 of table 4 , when the assumption of indexation to lagged inflation is replaced by the assumption of indexation to long-run

\footnotetext{
${ }^{11}$ Because in this economy monetary policy plays no role in the determination of real variables, figure 5 does not show the response of inflation and the nominal interest rate in this economy.
} 
inflation, then the optimal volatility of inflation falls tenfold to 0.2 percent per annum. A reason why the role of the precise nature of the indexation scheme in determining the degree of optimal inflation volatility did not emerge earlier in the related literature is that by focusing exclusively in the case of no indexation and zero long-run inflation, existing studies in effect concentrated in a special case of indexation to long-run inflation. The intuition for why the indexation scheme is related to the optimal degree of inflation volatility is relatively straightforward. Under indexation to lagged inflation, the distorting price dispersion induced by price stickiness is smaller than under indexation to long-run inflation. This is because when firms get the chance to reoptimize prices they need not fully incorporate expected future deviations of inflation from trend in their current markups, as they know that they will be allowed to keep up with aggregate price changes through indexation. On the other hand, when indexation is based on long-run inflation, it is crucial for firms to incorporate in their optimized prices the expected future deviations of inflation from trend. An economy with indexation to lagged inflation is in this sense closer to a flexible-price economy than an economy with indexation to long-run inflation. An obvious implication of our finding is that investigating what assumptions about indexation is empirically most compelling should be a high priority for the applied monetary research agenda.

Previous authors, notably Erceg, Henderson, and Levin (2000) have argued that the optimality of low inflation volatility is not robust to the introduction of sluggish factor price adjustment. Specifically, these authors extend the synthetic new Keynesian model to allow for nominal wage stickiness and find that full price stabilization is suboptimal. We find that this result generalizes to the richer economic environment studied here. Specifically, line 3 of table 4 shows the standard deviation associated with the best operational rule falls from 2 percent to 0.5 percent per annum when wage stickiness is removed.

\subsection{The Role of Money}

Optimal monetary policy induces a surprising positive relationship between the size of money demand and the optimal degree of interest rate and inflation volatility. In effect, in the baseline economy inflation and the nominal interest rate display a volatility of about 2 percent (see table 3). If one eliminates the demand for money by households by setting $\phi_{1}=0$, the volatilities of inflation and the nominal interest rate drop to 0.8 (see table 4). This effect appears at first as counterintuitive. For one would expect that the larger is the demand for money, the stronger is the incentive for optimal policy to smooth the opportunity cost of holding money, given by the nominal interest rate. This incentive is present in our model economy. But there is also a payoff for increasing interest rate volatility as the importance of 
Table 3: Aggregate Volatility Induced by Alternative Monetary Regimes

\begin{tabular}{lcccccc}
\hline \hline \multicolumn{5}{c}{ Optimized Rules $\hat{R}_{t}=\alpha_{\pi} E_{t} \hat{\pi}_{t-i}+\alpha_{y} E_{t} \hat{y}_{t-i}+\alpha_{R} \hat{R}_{t-1}$} \\
\hline & $\sigma_{c}$ & $\sigma_{h}$ & $\sigma_{m^{h}}$ & $\sigma_{y}$ & $\sigma_{\pi}$ & $\sigma_{R}$ \\
\hline Current-Looking Rules $(i=0)$ & & & & & \\
No Inertia $\left(\alpha_{R}=0\right)$ & 1.2 & 0.8 & 1.1 & 1.7 & 0.7 & 0.8 \\
Inertia $\left(\alpha_{R}=1\right)$ & 1.2 & 1.1 & 2.2 & 2.0 & 1.6 & 1.6 \\
$\quad$ Super Inertia $\left(\alpha_{R}=2\right)$ & 1.2 & 1.1 & 1.8 & 2.0 & 1.4 & 1.4 \\
\hline Backward-Looking Rules $(i=1)$ & & & & \\
No Inertia $\left(\alpha_{R}=0\right)$ & 1.2 & 1.1 & 2.1 & 2.0 & 1.6 & 1.6 \\
Inertia $\left(\alpha_{R}=1\right)$ & 1.2 & 1.1 & 1.8 & 2.0 & 1.3 & 1.3 \\
Super Inertial $\left(\alpha_{R}=2\right)$ & 1.1 & 0.6 & 1.9 & 1.4 & 1.5 & 1.4 \\
\hline Forward-Looking Rules $(i=-1)$ & 1.1 & 0.6 & 2.7 & 1.3 & 2.0 & 2.1 \\
$\quad$ No Inertia $\left(\alpha_{R}=0\right)$ & 1.3 & 1.2 & 2.6 & 2.1 & 2.0 & 2.0 \\
Inertia $\left(\alpha_{R}=1\right)$ & 1.3 & 1.2 & 2.7 & 2.1 & 2.0 & 2.0 \\
$\quad$ Super Inertia $\left(\alpha_{R}=2\right)$ & & & & & \\
\hline Simple Taylor Rule & & & & \\
$\left(\alpha_{R}=\alpha_{y}=0, \alpha_{\pi}=1.5\right)$ & 1.2 & 0.9 & 0.9 & 1.7 & 0.4 & 0.6 \\
\hline \hline
\end{tabular}

Note: For any variable $x_{t}, \sigma_{x}$ denotes its unconditional standard deviation. The variables $c_{t}, h_{t}, m_{t}^{h}$, and $y_{t}$ are measured as percentage deviations from their respective deterministic steady-state levels; $\pi_{t}$ and $R_{t}$ are in percent per annum. 
Table 4: Optimal Operational Rules: Sensitivity Analysis

\begin{tabular}{lccccccc}
\hline \hline \multicolumn{1}{c}{ Optimized Interest-Rate Rules } & & & & \\
$\hat{R}_{t}=\alpha_{\pi} E_{t} \hat{\pi}_{t-i}+\alpha_{y} E_{t} \hat{y}_{t-i}+\alpha_{R} \hat{R}_{t-1}$ & & & & \\
\hline & $i$ & $\alpha_{\pi}$ & $\alpha_{y}$ & $\alpha_{R}$ & $\sigma_{R}$ & $\sigma_{\pi}$ & $\sigma_{y}$ \\
\hline Baseline & -1 & 1.13 & -0.06 & 0 & 2.1 & 2.0 & 1.3 \\
Indexation to Long-Run Inflation & -1 & 0.19 & 0 & 1 & 0.1 & 0.2 & 1.6 \\
Flexible Wages $(\tilde{\alpha}=0.01)$ & -1 & 3 & -0.19 & 0 & 0.6 & 0.5 & 1.5 \\
Flexible Prices $(\alpha=0.01)$ & 1 & -0.69 & -0.31 & 2 & 3.5 & 3.7 & 0.9 \\
Higher Capital Utilization Costs $\left(\gamma_{2} / \gamma_{1}=2\right)$ & 0 & 1.44 & 0.25 & 0 & 3.4 & 3.3 & 1.4 \\
No Habit Formation $(b=0)$ & -1 & 1.13 & 0 & 0 & 1.5 & 1.3 & 1.8 \\
No Money Held by Households $\left(\phi_{1}=0\right)$ & 0 & 1.06 & 0 & 0 & 0.8 & 0.7 & 1.7 \\
No Money At All $\left(\phi_{1}=\nu=0\right)$ & -1 & 1.75 & 0.31 & 0 & 2.8 & 2.8 & 1.6 \\
\hline One Nominal Friction at a Time & & & & & & & \\
Sticky Prices Only $\left(\phi_{1}=\nu=\tilde{\alpha}=0\right)$ & 0 & 3 & 0 & 1 & 0.2 & 0.0 & 1.6 \\
Sticky Wages Only $\left(\phi_{1}=\nu=\alpha=0\right)$ & 0 & 1.5 & 0.25 & 0 & 3.5 & 3.4 & 1.6 \\
Household Money Only $(\nu=\alpha=\tilde{\alpha}=0)$ & 1 & 0.44 & -0.25 & 1 & 3.5 & 4.0 & 1.6 \\
Firm Money Only $\left(\phi_{1}=\alpha=\tilde{\alpha}=0\right)$ & 1 & -3 & -0.25 & 1 & 1.0 & 0.7 & 1.8 \\
\hline \hline
\end{tabular}

Notes: See tables 2 and 3.

money holdings increases. Specifically, the benefit is that higher interest rate volatility may achieve a lower average nominal interest rate, thus increasing average money holdings, which is welfare increasing, since money held by households enters into the utility function. The policy maker resorts to this cumbersome way of reducing the opportunity cost of holding money because by assumption he must work with an exogenously given target for inflation and the nominal interest rate. Comparing the means and standard deviations of the nominal interest rate in the benchmark economy with those of the economy in which households do not demand money, suggest that the policy maker resolves this mean-volatility tradeoff in favor of lower mean nominal interest rates at the cost of higher interest rate volatility. ${ }^{12}$

\subsection{Transitional Dynamics Matter}

The existing literature on macroeconomic stabilization says little about the role of initial conditions in shaping optimal policy. Typically, policy-evaluation studies are conducted on the basis of unconditional measures of welfare, which by design 'integrate away' the role of the initial state. We find that transitional dynamics are indeed an important factor

\footnotetext{
${ }^{12}$ The unconditional mean of the nominal interest rate in the models with and without money held by households are, respectively, 6.9 and 7.1 .
} 
Table 5: Unconditional Means Induced by Alternative Monetary Regimes

\begin{tabular}{|c|c|c|c|c|c|c|c|}
\hline \multicolumn{8}{|c|}{ Optimized Interest-Rate Rules $\hat{R}_{t}=\alpha_{\pi} E_{t} \hat{\pi}_{t-i}+\alpha_{y} E_{t} \hat{y}_{t-i}+\alpha_{R} \hat{R}_{t-1}$} \\
\hline & $c_{t}$ & $h_{t}$ & $m_{t}^{h}$ & $y_{t}$ & $\pi_{t}$ & $R_{t}$ & $V_{t}$ \\
\hline \multicolumn{8}{|c|}{ Current-Looking Rules $(i=0)$} \\
\hline No Inertia $\left(\alpha_{R}=0\right)$ & 0.1025 & -0.1018 & 0.0953 & -0.1248 & 4.1101 & 7.0657 & -156.4310 \\
\hline Inertia $\left(\alpha_{R}=1\right)$ & 0.1115 & -0.1437 & 0.0853 & -0.1749 & 4.2541 & 7.2099 & -156.3668 \\
\hline Super Inertia $\left(\alpha_{R}=2\right)$ & 0.1092 & -0.1365 & 0.0559 & -0.1671 & 4.2296 & 7.1852 & -156.3789 \\
\hline \multicolumn{8}{|c|}{ Backward-Looking Rules $(i=1)$} \\
\hline No Inertia $\left(\alpha_{R}=0\right)$ & 0.1088 & -0.14 & 0.0658 & -0.1702 & 4.2503 & 7.2061 & -156.3752 \\
\hline Inertia $\left(\alpha_{R}=1\right)$ & 0.1084 & -0.1344 & 0.363 & -0.1643 & 4.2237 & 7.1795 & -156.3826 \\
\hline Super Inertial $\left(\alpha_{R}=2\right)$ & 0.0759 & -0.06 & 0.3181 & -0.0776 & 4.0372 & 6.9930 & -156.5230 \\
\hline \multicolumn{8}{|c|}{ Forward-Looking Rules $(i=-1)$} \\
\hline No Inertia $\left(\alpha_{R}=0\right)$ & 0.0817 & -0.0498 & 0.6323 & -0.0635 & 3.9821 & 6.9373 & -156.5276 \\
\hline Inertia $\left(\alpha_{R}=1\right)$ & 0.1155 & 0.1543 & 0.1606 & -0.1873 & 4.2871 & 7.2429 & -156.3480 \\
\hline Super Inertia $\left(\alpha_{R}=2\right)$ & 0.1157 & -0.1554 & 0.1619 & -0.1888 & 4.2899 & 7.2457 & -156.3464 \\
\hline Simple Taylor Rule & & & & & & & \\
\hline$\left(\alpha_{R}=\alpha_{y}=0, \alpha_{\pi}=1.5\right)$ & 0.1002 & -0.1019 & 0.1242 & -0.1270 & 4.1124 & 7.0673 & -156.4342 \\
\hline
\end{tabular}

Notes: $c_{t}, h_{t}$, and $y_{t}$ are measured as percentage deviations from their deterministic steady-state levels; $\pi_{t}$ and $R_{t}$ are in percent per annum; and $V_{t} \equiv$ $E_{t} \sum_{j=0}^{\infty} \beta^{j} U\left(c_{t+j}-b c_{t-1+j}, m_{t+j}^{h}, h_{t+j}\right)$ is expressed in levels.

determining the choice of the optimal policy rule. This can be seen by comparing the conditional welfare numbers reported in table 2 with the unconditional expectation of lifetime utility, which are shown in the last column of table 5. Based on an unconditional measure of welfare, the optimal operational rule is in fact the worst of all rules shown in the table. By construction, the unconditional welfare measure is a weighted average of the conditional welfare levels associated with all possible values of the state vector with weights given by their unconditional probabilities. It follows that for some initial conditions the conditional welfare ranking reported in table 2 should be reversed as well. This result is indicative of the fact that the optimal operational rule lacks time consistency. In other words, if the monetary authority was given the chance to reoptimized the parameters defining the interestrate feedback rule after period 0 , it would in general not choose the the policy quadruple that was optimal from the point of view of period 0 .

The fact that welfare rankings appears not to be independent of the initial state of the economy suggests that it is important to consider relevant initial conditions. Here we explore the initial condition given by the unconditional expectation of the state vector in an economy in which monetary policy takes the form of a simple Taylor rule $\left(\hat{R}_{t}=1.5 \hat{\pi}_{t}\right)$. The reason 
Table 6: Comparing Three Alternative Welfare Measures

\begin{tabular}{l|c|c|c|c|c}
\hline \hline & & & Unconditional & \multicolumn{2}{c}{ Conditional Welfare } \\
Interest-Rate Rule & $\alpha_{\pi}$ & $\alpha_{y}$ & Welfare & $x_{0}=x$ & $x_{0}=E x_{t}^{S T R}$ \\
\hline Current-Looking Rules $(i=0)$ & & & & & \\
$\quad$ No Inertia $\left(\alpha_{R}=0\right)$ & 1.0625 & 0 & -156.4310 & -156.7227 & -156.5049 \\
$\quad$ Inertia $\left(\alpha_{R}=1\right)$ & 0.625 & 0.1250 & -156.3668 & -156.7237 & -156.5132 \\
$\quad$ Super Inertia $\left(\alpha_{R}=2\right)$ & 0.8125 & 0.3125 & -156.3789 & -156.7248 & -156.5133 \\
\hline Backward-Looking Rules $(i=1)$ & & & & & \\
$\quad$ No Inertia $\left(\alpha_{R}=0\right)$ & 1.3125 & 0.0625 & -156.3752 & -156.7233 & -156.5124 \\
$\quad$ Inertia $\left(\alpha_{R}=1\right)$ & 0.75 & 0.1250 & -156.3826 & -156.7243 & -156.5126 \\
$\quad$ Super Inertia $\left(\alpha_{R}=2\right)$ & -0.75 & -0.0625 & -156.5230 & -156.7250 & -156.5025 \\
\hline Forward-Looking Rules $(i=-1)$ & & & & & \\
$\quad$ No Inertia $\left(\alpha_{R}=0\right)$ & 1.1250 & -0.0625 & -156.5276 & -156.7220 & -156.4940 \\
Inertia $\left(\alpha_{R}=1\right)$ & 0.8125 & 0.1875 & -156.3480 & -156.7232 & -156.5138 \\
Super Inertia $\left(\alpha_{R}=2\right)$ & 1.6875 & 0.6250 & -156.3464 & -156.7237 & -156.5143 \\
\hline Simple Taylor Rule & 1.5 & - & -156.4342 & -156.7261 & -156.5095 \\
\hline \hline
\end{tabular}

Notes: (1) See notes to table 2. (2) $x_{t}$ denotes the state vector in period $t$, $x$ denotes the deterministic steady-state value of $x_{t}$, and $E x_{t}^{S T R}$ denotes the unconditional expectation of $x_{t}$ when the monetary policy takes the form of a simple Taylor rule $(S T R)$ of the form $\hat{R}_{t}=1.5 \hat{\pi}_{t}$.

we consider this initial condition is that the policy rule that induces it can be interpreted as a rough characterization of actual U.S. monetary policy post 1980.

Table 6 shows three alternative welfare measures for the 10 operational policies presented in table 2: namely, unconditional expected welfare, expected welfare conditional on the initial state being the deterministic steady state, and expected welfare conditional on the initial state being the mean of the state vector in an economy that follows a simple Taylor rule. An important result conveyed by table 6 is that changing the initial condition of the economy from the deterministic steady state to an arguably more relevant one given by the mean of the distribution of the state vector under a simple Taylor rule does not alter the fact that the real-interest-rate targeting rule $\hat{R}_{t}=1.125 E_{t} \hat{\pi}_{t+1}-0.0625 E_{t} \hat{y}_{t+1}$ welfare dominates all other 9 rules considered in table 2 . This result suggests that a monetary authority that has being following a simple Taylor rule in the past could find it beneficial to switch policy to a real interest-rate targeting rule like the optimal operational rule if the economy is in its average state. 


\subsection{Optimal Policy One Nominal Friction at a Time}

It is well known from the work of Goodfriend and King (1997) among many others that in a model where sluggish product price adjustment is the only nominal friction, optimal policy stabilizes inflation completely. That is, the optimal monetary policy calls for setting the variance of $\pi_{t}$ equal to zero. It is also well known that one way to implement this policy is by means of an interest-rate feedback rule with a very large inflation coefficient (Woodford, 2001). The existing literature containing this result is based on simple theoretical frameworks. Here we show that the same conclusions hold is the much richer and empirically plausible model studied in this paper. In effect, table 4 shows that if one shuts down all of the nominal rigidities present in our model but price stickiness by setting $\phi_{1}, \nu$, and $\tilde{\alpha}$ equal to zero - and thereby engineering a cashless economy with flexible wages - then the best interest-rate rule calls for a short-run inflation coefficient $\alpha_{\pi}$ equal to the upper bound of 3 imposed by our grid, and a long-run inflation coefficient, $\alpha_{\pi} /\left(1-\alpha_{R}\right)$, of infinity by making the rule inertial. Moreover, the optimal interest-rate rule is welfare dominated by a strict inflation targeting rule whereby the inflation rate is kept at its target level at all times, $\hat{\pi}_{t}=0$.

Not surprisingly, in a world where the only nominal friction stems from wage stickiness, inflation stabilization is no longer optimal. Table 4 shows that in this case the optimal level of inflation volatility is 3.5 percent per annum. Also as expected, in the economy with sticky wages only the volatility of wage inflation is smaller than the volatility of price inflation ( 0.8 versus 3.5 percent per year) whereas in the economy with sticky prices only it is the other way around ( 0.1 versus 0$)$. What is somewhat surprising is that the presence of wage stickiness does not call for stabilizing wage inflation. In the sticky-wage-only economy, the volatility of wage inflation under the optimal interest-rate rule is 0.8 percent per year whereas in the sticky-price-only economy it is only 0.1 percent per year. Interestingly, in the model we study in this paper, the presence of wage stickiness does not appear to introduce a meaningful inflation-output volatility tradeoff, as found in simpler setups (e.g., Erceg, Henderson, Levin, 2000). Specifically, under the optimized rule the volatility of output is the same, 1.6 percent, in the economies with sticky prices only, sticky wages only, and sticky wages and sticky prices only (i.e., no money).

In the economy where money demand by household represents the only nominal friction, optimal monetary policy is geared toward reducing the average opportunity cost of holding money to increase mean real money holdings, which enter the welfare index directly. Specifically, the mean of the nominal interest rate is 6.8 percent, compared to 7.2 in the economy

without money. As a result, real balances in the economy with money by households only are on average 2.4 percent above their steady-state level. The reduction in the average nominal 
interest rate is achieved at the costs of relatively high interest-rate volatility. As mentioned earlier, this awkward taste for nominal interest-rate volatility on the part of the central bank is induced by the exogeneity of the inflation target. If the inflation target was endogenous, the monetary authority should choose an inflation level in line with the Friedman rule, and, in the case of money being the only nominal friction, no interest-rate volatility. A different pattern emerges when the only nominal friction in the economy is a demand for money by firms. In this case, the mean-volatility tradeoff for the nominal interest rate is resolved in favor of interest-rate stability.

\section{Conclusion}

The contribution of this paper is to perform second-order accurate welfare evaluations of operational interest rate feedback rules in a large-scale, empirically compelling model of the U.S. business cycle. The stabilization policy problem in this economy is complicated by the presence of a multitude of nominal and real frictions including sticky wages and prices, a demand for money by households and firms, monopolistic competition, investment adjustment costs, habit formation, and variable costs of adjusting the degree of capacity utilization.

The key characteristic of the optimal operational rule is that it stabilizes the real interest rate. The presence of nominal rigidities play a significant role in shaping optimal monetary policy. This is reflected in the fact that when either one of the nominal rigidities is eliminated or when the price or wage indexation scheme is altered, then the form of the optimal operational rule changes significantly.

The optimal operational rule induces an equilibrium with a non-negligible degree of inflation volatility. This implication of optimal policy is sensitive to the particular indexation scheme assumed for prices and wages. In particular, when the baseline assumption of indexation to lagged price inflation is replaced by the assumption of indexation to the long-run level of inflation, then inflation volatility under the optimal operational rule drops significantly.

This paper can be extended in a variety of ways. One is to investigate how optimal policy changes as the sources of uncertainty driving business cycles is expanded. One alternative is to incorporate the rich set of shocks identified in econometric estimations of the model considered in this paper (e.g., Smets and Wouters, 2004).

The class of operational rules studied in this paper is clearly not exhaustive. It would be of interest to investigate whether the inclusion of macroeconomic indicators other than those considered here would improve the policy makers ability to stabilize the economy. In particular, the related literature has emphasized the use of measures of the output gap that 
are different from that used in the present study. Additionally, it has been argued that in models with nominal wage and price rigidities the optimal policy should target an average of wage and price inflation as opposed to only price inflation, which is the case analyzed in this paper.

The optimal policy problem analyzed in this paper takes the central bank's inflation target as exogenously given. A natural extension is to endogenize this variable. However, in the theoretical framework studied here, the optimal inflation target is the one associated with the Friedman rule. This is because the assumption of full indexation to past inflation implies the absence of inefficient price and wage dispersion in the long run. Thus the only remaining nominal friction is the demand for money by households and firms. The elimination of these frictions calls for driving the opportunity costs of holding money to zero in the long run. In other words, the zero bound on nominal interest rate binds in the non-stochastic steady state. Unfortunately, the perturbation technique employed in this paper is ill suited to handle this case. Therefore, analyzing the case of an endogenous inflation target entails either changing the model so that the Friedman rule is no longer optimal in the long-run or adopting alternative numerical techniques for computing welfare accurately up to secondorder or higher.

A finding of this paper is that the initial state of the economy plays a role in determining the parameters defining the optimal interest-rate rule. This finding suggests that the optimal operational rule identified here is time inconsistent. Throughout the paper we assume that the government is able to commit to the policy announcements made at time 0 . It would be of interest to compute optimal operational rules in an environment without commitment.

Finally, the current study limits attention to the special case of passive fiscal policy, taking the form of a balanced-budget rule with lump-sum taxation. It is well known that the set of operational monetary rules depends on the stance of fiscal policy. For instance, the determinacy properties of the rational expectations equilibrium associated with a particular monetary rule can change as fiscal policy is altered. Therefore, it would be of interest to introduce operational fiscal rules as an additional policy instrument. 


\section{References}

Altig, David, Lawrence J. Christiano, Martin Eichenbaum, and Jesper Linde, "Technology Shocks and Aggregate Fluctuations," manuscript, Northwestern University, 2003.

Calvo, Guillermo A., "Staggered prices in a utility-maximizing framework," Journal of Monetary Economics 12, 1983, 383-98.

Carlstrom, Charles T. and Timothy S. Fuerst, "Investment and Interest Rate Policy: A Discrete Time Analysis," manuscript, Bowling Green State University, March 4, 2003.

Christiano, Lawrence J. and Martin Eichenbaum, "Current Real Business Cycle Theory and Aggregate Labor Market Fluctuations," American Economic Review 82, 1992, 430-450.

Christiano, Lawrence J., Martin Eichenbaum, and Charles Evans, "Nominal Rigidities and the Dynamic Effects of a Shock to Monetary Policy," Northwestern University, August 27, 2003.

Clarida, Richard; Gali, Jordi; and Gertler, Mark, "Monetary Policy Rules in Practice: Some International Evidence," European Economic Review 42, June 1998, 1033-67.

Clarida, Richard, Jordi Galí, and Mark Gertler, "The Science of Monetary Policy: A New Keynesian Perspective," Journal of Economic Literature 37, 1999, 1661-1707.

Cooley, Thomas F. and Edward C. Prescott, "Economic Growth and Business Cycles," in Thomas F. Cooley, ed., Frontiers of Business Cycle Research, Princeton, New Jersey: Princeton University Press, 1995, pp. 1-38.

Erceg, Christopher J., Henderson, Dale W., and Levin, Andrew T., "Optimal Monetary Policy With Staggered Wage and Price Contracts," Journal of Monetary Economics 46, October 2000, 281-313.

Goodfriend, Marvin and Robert G. King, "The New Neoclassical Synthesis and the Role of Monetary Policy," in Ben Bernanke and Julio Rotemberg Eds., NBER Macroeconomics Annual 1997, Cambridge, MA: MIT Press, 1997, pp. 231-283.

Kim, J., S. Kim, E. Schaumburg, and C. Sims, "Calculating and Using Second Order Accurate Solutions of Discrete Time Dynamic Equilibrium Models," mimeo, Princeton University, 2003.

Ireland, Peter, "A Small, Structural, Quarterly Model for Monetary Policy Evaluation," Carnegie-Rochester Conference Series on Public Policy 47, December 1997, 83-108.

Kimball, Miles S., "The Quantitative Analytics of the Basic Neomonetarist Model," Journal of Money, Credit and Banking 27, November 1995, 1241-1277.

King, Robert G. and Sergio T. Rebelo, "Resuscitating Real Business Cycles," in John B. Taylor and Michael D. Woodford, eds., Handbook of Macroeconomics, Amsterdam and New York: Elsevier, 1999, 927-1007. 
Kollmann, Robert, "Welfare Maximizing Fiscal and Monetary Policy Rules," mimeo, University of Bonn, March 2003.

Lucas, Robert E, Jr, Models of business cycles, Yrjo Jahnsson Lectures series. London and New York: Blackwell, 1987.

Lucas, Robert E. Jr. and Stokey, Nancy L., "Optimal Fiscal and Monetary Policy in an Economy Without Capital," Journal of Monetary Economics 12, 1983, 55-93.

Rotemberg, Julio J. and Woodford, Michael D., "Oligopolistic Pricing and the Effects of Aggregate Demand on Economic Activity," Journal of Political Economy 100, December 1992, 1153-1207.

Rotemberg, Julio J., and Michael Woodford, "Interest Rate Rules in an Estimated Sticky Price Model," in John B. Taylor, ed., Monetary policy rules, NBER Conference Report series. Chicago and London: University of Chicago Press, 1999, 57-119.

Schmitt-Grohé, Stephanie and Martín Uribe, "Optimal Fiscal and Monetary Policy Under Imperfect Competition," Journal of Macroeconomics, forthcoming, 2004a.

Schmitt-Grohé, Stephanie and Martín Uribe, "Optimal Simple And Implementable Monetary and Fiscal Rules," NBER working paper no. 10253, January 2004b.

Schmitt-Grohé, Stephanie and Martín Uribe, "Solving Dynamic General Equilibrium Models Using a Second-Order Approximation to the Policy Function," Journal of Economic Dynamics and Control 28, January 2004c, 755-775.

Schmitt-Grohé, Stephanie and Martín Uribe, "Optimal Fiscal and Monetary Policy under Sticky Prices," Journal of Economic Theory 114, February 2004d, 198-230.

Smets, Frank and Raf Wouters, "Shocks and Frictions in US Business Cycles: A Bayesian DSGE Approach," manuscript, European Central Bank, April 21, 2004.

Sveen, Tommy and Lutz Weinke, "Inflation and Output Dynamics with Firm-Owned Capital," mimeo, Universitat Pompeu Fabra, 2003.

Taylor, John B., "Discretion versus Policy Rules in Practice," Carnegie Rochester Conference Series on Public Policy 39, December 1993, 195-214.

Woodford, Michael D., "The Taylor Rule and Optimal Monetary Policy," American Economic Review 91, January 2001, 232-237.

Woodford, Michael, Interest and Prices: Foundations of a Theory of Monetary Policy, Princeton: Princeton University Press, 2003.

Woodford, Michael D., "Inflation Targeting and Optimal Monetary Policy," manuscript, Princeton University, October 8, 2003.

Yun, Tack, "Nominal price rigidity, money supply endogeneity, and business cycles," Journal of Monetary Economics 37, 1996, 345-370. 